Parenting Values Moderate the Intergenerational Transmission of Time Preferences

Anne Ardila Brenøe, Thomas Epper

November 2019 Discussion Paper no. 2019-17

School of Economics and Political Science, Department of Economics 


$\begin{array}{ll}\text { Editor: } & \text { Vanessa Pischulti } \\ & \text { University of St.Gallen } \\ & \text { School of Economics and Political Science } \\ & \text { Department of Economics } \\ & \text { Müller-Friedberg-Strasse 6/8 } \\ & \text { CH-9000 St.Gallen } \\ & \text { Phone +4171 224 23 07 } \\ & \text { Email seps@unisg.ch } \\ & \text { School of Economics and Political Science } \\ & \text { Department of Economics } \\ & \text { University of St.Gallen } \\ \text { Publisher: } & \text { Müller-Friedberg-Strasse 6/8 } \\ & \text { CH-9000 St.Gallen } \\ & \text { Phone +41 71 224 23 07 } \\ & \text { http://www.seps.unisg.ch }\end{array}$




\title{
Parenting Values Moderate the Intergenerational Transmission of Time Preferences ${ }^{1}$
}

\author{
Anne Ardila Brenøe, Thomas Epper
}

Author's address:

\author{
Prof. Anne Ardila Brenøe \\ Department of Economics \\ University of Zurich \\ Schönberggasse 1 \\ $\mathrm{CH}-8001$ Zurich \\ anne.brenoe@econ.uzh.ch \\ Prof. Dr. Thomas Epper \\ Institute of Economics (FGN) \\ University of St.Gallen \\ Varnbüelstrasse 19 \\ $\mathrm{CH}-9000$ St.Gallen \\ thomas.epper@unisg.ch
}

\footnotetext{
${ }^{1}$ We thank Thomas Dohmen, David Dorn, Orla Doyle, Mette Ejrnæs, Ernst Fehr, Lukas Kiessling, Gregers Nytoft Rasmussen, Nicol'as Salamanca, Daniel Schunk, Matthias Sutter, David Yanagizawa-Drott, Roberto Weber, the Center for Economic Behavior and Inequality (CEBI), and seminar participants at DGPE Behavior and Incentives, the Copenhagen Education Network Workshop 2018, the CEBI Lunch Seminar 2018, the Education and Health Group at the University of Copenhagen, the IZA Brownbag Seminar, the Faculty Seminar at the University of Zurich, the Brown Bag Seminar at the University of St.Gallen, the Young Swiss Economists Meeting 2019, the European University Institute, the KIDS workshop 2019, and the EALE conference 2019 for helpful discussions and comments.
} 


\begin{abstract}
We study the intergenerational transmission of time preferences in a setting without reverse causality concerns. We find substantial transmission of patience from parents to children, which is insensitive to the inclusion of comprehensive sets of administratively reported controls and persists as children age. We further explore heterogeneity in the transmission with respect to two theoretically important but distinct dimensions of socialization through which parents can influence children's traits: parenting values and parental involvement. Our results show that, in contrast to authoritative parents, authoritarian and permissive parents transmit patience to their offspring. Meanwhile, parental involvement is not an important moderator. These patterns replicate in an independent sample with richer measures of parental involvement.
\end{abstract}

\title{
Keywords
}

Intergenerational transmission, time preferences, patience, parenting style, parenting values, parental involvement

\section{JEL Classification}

D15, J12, J24, J62 


\section{Introduction}

Patient people generally experience better lifetime outcomes than their impatient peers. ${ }^{1}$ Time preferences elicited during childhood are predictive of how individuals fare in later life-for instance, in terms of education, health, and earnings (Golsteyn, Grönqvist and Lindahl, 2014; Mischel, Shoda and Peake, 1988). If parents transmit time preferences to their children, parental patience may thus have long-term consequences for how their children fare during adulthood. Such transmission is therefore also important for society as a whole and could, in part, explain the well-documented transmission of social disadvantage across generations ${ }^{2}$ Yet, we do not know much about the evolution of time preferences, the transmission of these preferences across generations, and the mechanisms that are relevant for propagation from parents to children 3 It is increasingly important to better understand these issues given the generally low social mobility and increasing economic inequality worldwide (Jones, 2015).

In this paper, we address the following key questions on preference transmission: Are time preferences passed on to the next generation? If so, does the transmission persist or fade out as children age? How relevant is parenting (parenting values and parental involvement) as a socialization device through which preferences carry over from parents to offspring? Understanding whether intergenerational correlations in preferences are indeed due to the transmission from parents to children and how parenting influences such transmission is challenging given the data sources usually available. There are three reasons for these challenges. First, it is rare to have validated time preference measures for both parents and children in the same data set. Second, even with such data at hand, the availability of sufficiently rich measures of family socialization is scarce. Third, given the typically short time frame between the elicitation of time preferences of both generations, there are inevitable concerns regarding reverse causality and spurious intergenerational correlations due to common shocks.

To circumvent these empirical challenges, we combine rich survey data on preferences, parenting values, parental time investments, and child-rearing practices with

\footnotetext{
${ }^{1}$ See e.g. Ayduk et al. (2000); Chabris et al. (2008); Epper et al. (2019b); Golsteyn, Grönqvist and Lindahl (2014); Meier and Sprenger (2012); Mischel, Shoda and Peake (1988); Shoda, Mischel and Peake (1990); Sutter et al. (2013).

${ }^{2}$ See e.g. Chetty et al. (2014); Landersø and Heckman (2017); Solon (1992).

3 Only a few existing studies examine intergenerational correlations in time preferences but they have some important limitations related to the timing of the measurement of preferences and the availability of data to explore potential channels for the transmission process, as explained later in the main text. For a detailed overview of the few existing studies on the transmission of time preferences, see Appendix Table B1.
} 
high-quality administrative data, including exceptionally rich information on socioeconomic status (SES). In particular, we use a unique, representative Danish survey that asks parents and children the same validated, intertemporal choice question four decades apart. This large time span between the elicitation of the preferences of parents (they were not parents at the time of measurement) and children thereby eliminates any concerns regarding reverse causality. The survey furthermore includes information on parenting values and parental involvement, allowing us to dig into the "black box" of socialization by carefully studying two distinct and theoretically relevant aspects of parenting that have been hypothesized to be the transmission channel of time preferences across generations (Bisin and Verdier, 2001, Doepke and Zilibotti. 2017). Finally, the availability of administrative data allows for the inclusion of comprehensive sets of controls, which further enable us to rule out that socioeconomic factors drive the transmission process.

We present three main results. First, we show that there is a substantial transmission of patience from parents to children. This intergenerational correlation of preferences is insensitive to the inclusion of rich vectors of administratively reported controls, including grandparental and parental socioeconomic background characteristics and child endowments, such as birth weight, IQ, and education. Second, the correlation between parental and offspring preferences does not vary by child age. Third, we illustrate that parenting values, which are proxying authoritarian and permissive parenting styles, are key moderators of the patience transmission. In contrast, parental involvement is not a relevant margin for heterogeneity in the transmission process. Because of the possibility that the latter finding might be due to the lack of sufficiently rich data on parental time investments, we further complement our primary analysis with a different, independent survey with richer measures on such inputs. All our results on moderators replicate in this second sample.

This paper brings new insights into the literature on intergenerational transmission of time preferences and potentially of other economic preferences, to the extent that the transmission process of such preferences shares channels through which parents transmit preferences to children. The small but emerging literature on the intergenerational transmission of economic preferences generally finds that parents' and children's time, risk, and social preferences correlate positively 4 However, this literature faces two major empirical limitations regarding the timing of preference elicitation and the ability to study channels of the transmission process. The fact that preferences of both generations typically are elicited within relatively short time

4E.g. Alan et al. (2017); Brown and van der Pol (2015); Chowdhury, Sutter and Zimmermann (2018); Dohmen et al. (2012); Gauly (2016); Giulietti, Rettore and Tonini (2016); Kosse and Pfeiffer (2013); Zumbuehl, Dohmen and Pfann (2018). 
frames (most commonly contemporaneously) leaves open whether it is: (i) parents who transmit preferences to children, (ii) children who affect parents' preferences, or (iii) the common environment that shapes both generations' preferences. Children with problems paying attention, for instance, typically react more impatiently and might, through their behavioral problems, lower parents' patience (case ii). Another important worry is that transitory shocks to the common environment might affect parents and children simultaneously, making their preferences appear similar even if they in reality were uncorrelated (case iii). For instance, a bad night's sleep (due to a thunderstorm or a heatwave) might make both parents and children appear impatient (more similar) than in the absence of such a shock. Or, due to temporary distress, such as children's exam periods or parental unemployment (which potentially could last some months or even a few years), both parents and children might react less patiently over a period of time in their survey responses.

Besides documenting intergenerational correlations in contemporaneously measured preferences, a crucial but much less studied topic is which mechanisms transmit preferences across generations. Bisin and Verdier (2001) theoretically study the dynamics of preferences across generations in a model with paternalistic altruism. They argue that each parent evaluates their child's actions from their own perspective and therefore, the parent always attempts to socialize the child to adopt the parent's preferences. Based on this and the conjecture that spending more time with the child enhances the adaptation and imitation process, Alan et al. (2017) and Zumbuehl, Dohmen and Pfann (2018) hypothesize that more-involved parents more strongly transmit preferences to their children. Relatedly, Doepke and Zilibotti (2017) build a model to study the role of parenting style in the intergenerational transmission of preferences by combining parental altruism and a paternalistic motive. In their model, the parent cares both about the child's current well-being (Beckerian altruism) and future well-being (paternalism). Due to children's natural preferences and inclinations for more short-sighted pleasure, the parent might disagree with the child's actions and therefore intervene through their parenting style (the paternalistic motive).

Inspired by developmental psychology (going back to Baumrind, 1967), Doepke and Zilibotti (2017) distinguish between three parenting styles: authoritarian, authoritative, and permissive. These parenting styles differ by the relative importance parents attach to the two broad dimensions of demandingness (control) and responsiveness (freedom and warmth) in their way of raising children.5 Authoritarian par-

${ }^{5}$ For more details and references, see e.g. Cobb-Clark, Salamanca and Zhu (2016); Doepke and Zilibotti (2019); Maccoby and Martin (1983). 
ents restrict their children's choices to impose their will (i.e. they exhibit high control and low freedom). Permissive parents, in contrast, refrain from influencing their children's choices by displaying low demandingness and granting a high degree of freedom. Finally, authoritative parents attempt to influence their offspring's preferences so that the child makes his or her own decisions but makes decisions that parents believe are conducive to success in life (high control and high freedom). In the case of time preferences, we would expect that authoritative parents aim to influence children to become more patient regardless of the parent's own time preferences (as patience is associated with better outcomes). Thus, we hypothesize that the transmission of patience from authoritative parents to their children is weak or absent.

In contrast to the theoretical models, the empirical literature offers only scarce evidence on actual moderators of the transmission process. However, in light of the theoretical models (especially the one by Bisin and Verdier, 2001), the general interpretation of the empirical findings of intergenerational correlations in economic preferences is that socialization is an important mechanism (e.g. Dohmen et al. 2012, Gauly, 2016).6 Yet, socialization has many facets, and it is therefore not clear what aspects of the childhood family environment drives the preference transmission.

Our study is the first to seriously dig into aspects of the family environment that characterize parent-child interactions to examine relevant moderators of the intergenerational transmission of time preferences. We do this by focusing on the relative importance of parenting values and parental involvement as separate dimensions of socialization, in a setting without the previously mentioned common measurement problems. Whether time spent with children moderates the transmission is likely to depend critically on how this time is actually spent. Moreover, even in the case of low parental time investment, the parent might still have a strong influence on their child's acquisition of traits. The parent's decision on where the child spends his or her time when not with the parent is, for instance, likely to depend on the parent's values.

${ }^{6}$ Other than cultural factors (and, in particular, socialization), genes are another arguably important mechanism for the moderation of preference transmission. Robalino and Robson (2013) review the empirical literature supporting genetic and cultural transmission and conclude that both factors are important. For instance, comparing monozygotic with dizygotic twins, Cesarini et al. (2009) conclude that approximately 25 percent of individual variation in preferences for giving and risk are explained by genetic differences. Benjamin et al. (2012) consider a wider set of political and economic preferences, including patience, and find that the estimated fraction of phenotypic variation of the traits explainable by genes (they use a method to compute the distance between dense single nucleotide polymorphisms (SNPs)) is about one-half of the narrow heritability estimated by twin studies. While our setup permits careful controls for family factors, our data do not include enough identical or fraternal twins for a detailed investigation of genetic transmission. Meanwhile, we have explored whether the transmission is weaker for non-biologically related child-parent pairs. This is not the case; see footnote 20 for details. 
We show that authoritarian and permissive parents transmit patience to their offspring, while authoritative parents do not. This is consistent with the theoretical framework of Doepke and Zilibotti (2017), as authoritative parents attempt to mold the child's preferences such that the child chooses what is conducive to success in life regardless of the parents' preferences. At the same time, we find no heterogeneity in the intergenerational transmission of time preferences by parental involvement. Given the correlation between parenting and SES, we further test the robustness of our heterogeneity results by allowing for heterogeneity in the patience transmission by SES (measured by an exceptionally rich, register-based index). We can rule out even small degrees of heterogeneity with respect to SES. Taken together, our results suggest that how parents interact with their children is more important than how often they do so and that the actual parenting style plays a more important role than the socioeconomic environment parents and children share when living together.

This paper relates to the small strand of literature that examines mechanisms of intergenerational correlations of other traits. Two notable studies empirically test whether the intergenerational correlation in contemporaneously elicited risk preferences and trust attitudes is heterogeneous with respect to parental involvement. Alan et al. (2017) find that maternal academic involvement is a relevant moderator of the correlation between mothers' and daughters' risk preferences, while Zumbuehl, Dohmen and Pfann (2018) show that more-involved parents (both mothers and fathers) have children who are more similar to them (the parents) with respect to risk and trust preferences.7

This paper also contributes to a body of literature that focuses on the development of economic and social preferences (for a recent review, see e.g. Sutter, Zoller and Glätzle-Rützler, 2019). Children's preferences develop substantially with age; for instance, Andreoni et al. (2019) document that children become more patient during childhood. Moreover, Liu and Zuo (2019) show that culture shapes risk preferences among primary school children and that their preferences are malleable to new environments. A few recent studies further provide causal evidence on the malleability of children's preferences (Alan and Ertac, 2018; Cappelen et al., 2019; Kosse et al. 2019). Finally, our paper has broader ties to a strand of literature examining the impact of parenting on child development. In particular, time investments and parenting quality in early childhood have been documented to improve child cognitive and socio-emotional skills (Agostinelli and Sorrenti, 2018; Attanasio et al., 2019; Bono

Zumbuehl, Dohmen and Pfann (2018) further show that children of more-involved parents according to their index are less impatient (they find no such differences for impulsiveness). However, they do not find heterogeneity in terms of the similarity between parents' and children's impatience with respect to parental involvement, in line with our finding. 
et al., 2016; Doyle, 2019).

\section{Data}

Our main data sources are the Danish Longitudinal Survey of Youth (DLSY) and DLSY-Children, which we link to high-quality administrative data on the full Danish population from 1980 through 2016. This combined data set provides unique possibilities for studying the intergenerational transmission of time preferences. The DLSY is a longitudinal study of 3,151 individuals born around 1954, whom we will refer to as parents. In 1968, these original respondents attended 152 different seventh-grade classes that were sampled to be nationally representative. The parents have subsequently been interviewed throughout their adult life with high response rates; around 75 percent of the original individuals participated in the last wave in 2004. In addition, the parents of the respondents (henceforth referred to as grandparents) were interviewed in 1969, making it possible to control for the parents' socioeconomic environment during their childhood. Finally, all the DLSY respondents, children who were at least 14 years old, were interviewed in 2010, with an extraordinarily high response rate of 81 percent. We therefore have information on three generations: grandparents, parents, and children.

We link the survey data to rich administrative data, including the Medical Birth Registry and several separate registers on education, income, (un)employment, fertility, and family structure. Therefore, in addition to the ample information on grandparents' SES during parents' childhood observed in the DLSY, we observe the SES experienced by the children during their childhood. We observe both parents' complete fertility history, labor market experience, and educational attainment. Based on these rich measures of parental SES, we construct an SES index (standardized with a mean of zero and a standard deviation of one), using the first principal component from a principal component analysis. For the children, we observe their date of birth, birth outcomes, and educational attainment by 2016. The rest of this section describes the main measures used for the analysis, while Data Appendix A supplements with additional details.

\subsection{Measure of Time Preferences}

In 1973 (at age 19), the parents answered a question regarding their time preferences. The question was:

If you were offered three jobs now and you could choose, which one would you take? 
(a) a job with average pay right from the beginning,

(b) a job with low pay the first two years, but high pay later, or

(c) a job with very low pay the first four years, but very high pay later.

In what follows, we categorize respondents answering (b) or (c) as patient. Using all three possible responses does not, however, change our conclusions 8 The children answered the same question nearly four decades later, in 2010, when they were between 14 and 40 years old, with an average age of 27. The timing of the parents' elicitation of time preferences allows us to rule out any issue of potential reverse causality, as only 2.8 percent $(N=87)$ of the children were born by 1973 , and only ten children were more than one year old. As a robustness check, however, we exclude children born at the time of the parents' response to the time preference question and reach similar results. Thus, our empirical setup gives us the power to study intergenerational transmission of patience in the absence of reverse causality concerns.

We observe responses to the intertemporal choice question for 3,101 children and 1,829 parents. Table 1 presents descriptive statistics for the full sample. While 64.8 percent of children are patient, 74.2 percent of parents are patient. This discrepancy between the rates of parent and child patience is unlikely to be due to cohort differences in time preferences but rather, is likely due to the nature of the question. Older children (those in their 3os) tend to be less patient than younger children (Appendix Figure $\mathrm{B}_{1}$ ), which is most likely due to the framing of the question. When restricting the sample of children to those in a similar age range (18-20 years) as when parents answered the time preference question, the share of patient children ( 72.8 percent) is similar to that of parents (73.8 percent) (Appendix Table B2 . Considering gender differences in patience, 73.9 percent of mothers, 75.4 percent of fathers, 61.9 percent of daughters, and 67.9 percent of sons are patient.9 The sample is balanced with respect to child and parent gender. On average, children have 1.5 siblings, while parents to the children in the sample have 2.2 children by 2016 and have 1.7 children in the sample (54.7 percent have at least two children in the sample). Seventy-three percent

\footnotetext{
${ }^{8}$ We also considered a model taking into account all three possible responses in the intertemporal choice question. Appendix Table $\mathrm{B}_{3}$ shows the results from ordered probit models, suggesting that we do not lose much from generalizing parental and child time preferences to a binary indicator for patience rather than considering the original three categories in the survey question.

9 Experiments confronting subjects (usually students at Western universities) with sooner smaller versus later larger rewards typically find that females are more patient than males (see e.g Dittrich and Leipold, 2014). In contrast, Falk et al. (2018) show that, in representative samples across 76 countries, men are statistically significantly more patient in one-third of the countries, while women are more patient in only five countries. Therefore, given that we also have a nationally representative sample, the gender gap in patience in favor of sons is not prominent.
} 
Table I

Descriptive Statistics

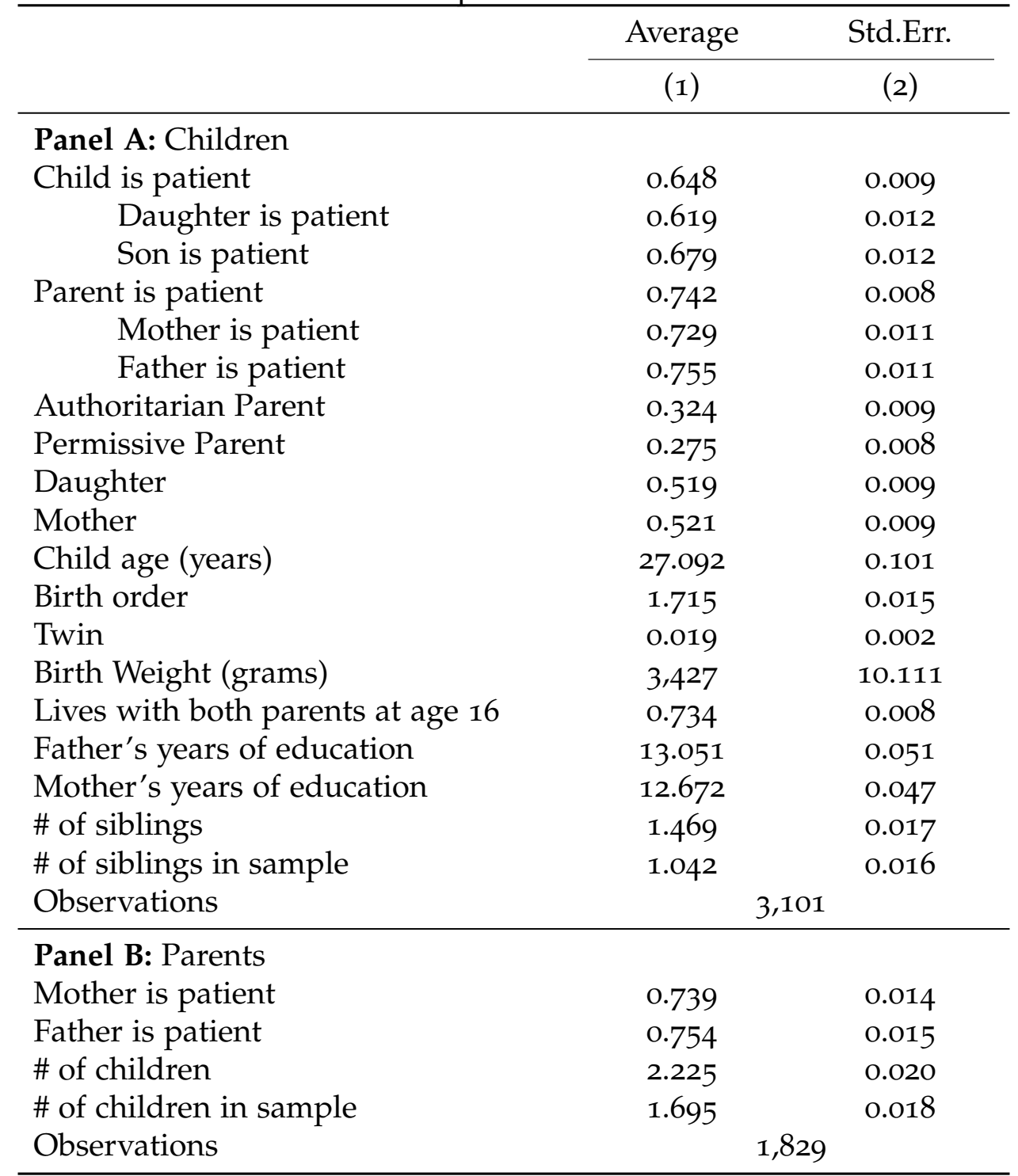

Note: This table presents descriptive statistics for the sample of children and their parents. Panel A contains means and standard errors for all children with a measure of their own and their parent's time preferences. Panel B contains the respective information for all parents of the children in Panel A. Note that we observe one parent per family only, i.e. either the mother or the father. Differences between Panel A and B can be explained by the fact that parents may have multiple children. 
of children lived with both biological parents at age 16 and their parents have, on average, completed around 13 years of education.

In comparison to experimental measures of time preferences (see e.g Frederick, Loewenstein and O'Donoghue, 2002: Epper, Fehr-Duda and Bruhin, 2011; Attema et al., 2016; Cohen et al., forthcoming), our survey measure has both advantages and disadvantages. The possibly most important advantages are that our survey question is short, simple, and less abstract than typical intertemporal choices employed in experiments. Specifically, our question asks subjects about their choice in a real-life situation with substantial economic consequences. This contrasts with experimental measures that typically ask subjects to repeatedly choose between sooner smaller amounts and later larger amounts (usually materializing within some weeks or a few months). This context-dependence might also be viewed as a shortcoming of our measure, in that considerations other than pure time preferences might lead subjects to choose a particular wage profile. Risk-averse individuals may, for instance, choose the average pay, fearing they would not reach the high pay (although the question does not explicitly associate risk with future pay raises).

Our patience indicator is both internally and externally valid. Epper et al. (2019b) document that the DLSY measure is highly predictive of time preferences elicited in an experiment with real monetary incentives among a broad and heterogeneous population born between 1967 and 1986 (Appendix Figure B2). Furthermore, examining the validity of our measure in an experiment with a large representative sample of the Danish population, Epper et al. (2019a) find that our survey measure is a good predictor for experimentally elicited time preferences. Epper et al. (2019b) further show for our sample of parents that the subjects we classify as patient have a consistently higher percentile rank in the within-cohort wealth distribution over a 15-year period (Appendix Figure $\mathrm{B}_{3}$ ).

Finally, the individuals we categorize as being patient face significantly better socioeconomic outcomes in adulthood, even when controlling for a wide range of childhood family characteristics (Table 2). For instance, patient parents score one-fifth of a standard deviation better on the SES index. Moreover, patient mothers (fathers) have 0.42 (o.61) more years of education and earn 43 (27) log-points more from age 26 through age 50 than impatient mothers (fathers). Similarly, patient daughters (sons) attained 0.50 (0.53) more years of education by 2016. These findings demonstrate that the DSLY measure captures patience well and that it is a good predictor of reallife economic outcomes. Appendix Table $\mathrm{B}_{4}$ further explores associations between parents' time preferences and fertility preferences at age 22 and their realized lifetime fertility. Women's fertility preferences are independent of their time preferences, 
while patient women are less likely to have children early. In contrast, patient men are more likely, at age 22, to desire having any children and are accordingly more likely to have (recognized) children by age 62 .

Table 2

Associations Between Patience and Socioeconomic Status

\begin{tabular}{|c|c|c|c|c|c|c|}
\hline & (1) & (2) & （3） & (4) & (5) & (6) \\
\hline & \multicolumn{5}{|c|}{ Parents by age 50} & Child \\
\hline & $\begin{array}{l}\text { SES } \\
\text { Index }\end{array}$ & $\begin{array}{l}\text { Educa- } \\
\text { tion } \\
\text { (years) }\end{array}$ & $\begin{array}{l}\text { Unem- } \\
\text { ploy- } \\
\text { ment }\end{array}$ & $\begin{array}{l}\text { Work } \\
\text { Experi- } \\
\text { ence }\end{array}$ & $\begin{array}{l}\text { Log } \\
\text { (Earn- } \\
\text { ings) }\end{array}$ & $\begin{array}{l}\text { Educa- } \\
\text { tion } \\
\text { (years) }\end{array}$ \\
\hline $\begin{array}{l}\text { Panel A: Women } \\
\text { Patient }\end{array}$ & $\begin{array}{l}0.16^{* *} \\
(0.06)\end{array}$ & $\begin{array}{l}0.42^{* *} \\
(0.18)\end{array}$ & $\begin{array}{c}-0.81^{* * *} \\
(0.19)\end{array}$ & $\begin{array}{c}2.58^{* * *} \\
(0.59)\end{array}$ & $\begin{array}{l}0.43^{* * *} \\
(0.14)\end{array}$ & $\begin{array}{l}0.50^{* * *} \\
(0.10)\end{array}$ \\
\hline Observations & 1,369 & 1,369 & 1,369 & 1,369 & 1,369 & 1,807 \\
\hline Average & 0.064 & 12.181 & 1.863 & 21.012 & 11.450 & 14.164 \\
\hline $\begin{array}{l}\text { Panel B: Men } \\
\text { Patient }\end{array}$ & $\begin{array}{l}0.21^{* * *} \\
(0.06)\end{array}$ & $\begin{array}{l}0.61^{* * *} \\
(0.19)\end{array}$ & $\begin{array}{c}-0.42^{* * *} \\
(0.14)\end{array}$ & $\begin{array}{c}0.78 \\
(0.58)\end{array}$ & $\begin{array}{l}0.27^{* *} \\
(0.12)\end{array}$ & $\begin{array}{l}0.53^{* * *} \\
(0.11)\end{array}$ \\
\hline $\begin{array}{l}\text { Observations } \\
\text { Average }\end{array}$ & $\begin{array}{l}1,370 \\
0.073\end{array}$ & $\begin{array}{c}1,370 \\
12.943\end{array}$ & $\begin{array}{l}1,370 \\
1.322\end{array}$ & $\begin{array}{l}1,370 \\
21.814\end{array}$ & $\begin{array}{c}1,370 \\
11.916\end{array}$ & $\begin{array}{l}1,666 \\
13.560\end{array}$ \\
\hline
\end{tabular}

Note: Standard errors in parentheses, clustered at the parent school level. ${ }^{*} p<0.1{ }^{* *} p<0.05$, ${ }^{* * *} p<0.01$. Each panel-column presents the results from separate regressions. The sample of parents corresponds to the original DLSY respondents who have at least one child. The sample of children are children to the DLSY parents. All models include Parent demographics, Parent School FE, and Grandparent SES (see the table note in Table 4 for details). Column (6) also include Child demographics. SES Index (standardized with mean zero and standard deviation one) is the first principal component from a principal component analysis; see Appendix Table $\mathrm{A}_{3}$ Education measures the length of highest completed education in years by 2016. Unemployment measures the cumulative length of unemployment between 1980-2004. Work Experience measures the cumulative length of work experience between 1964-2004. Log(Labor Earnings) is the natural logarithm of average annual labor earnings between 1980-2004.

\subsection{Definition of Parenting Moderators}

To explore the relevance of parenting as a socialization device through which parents transmit patience to their children, we consider parenting values (to proxy for parenting style) and parental involvement. Parenting styles are generally difficult to measure; the literature deals with this in two different ways. A common way to proxy for parenting styles is to measure actual parenting practices either reported by the parent or the child (e.g. Chan and Koo, 2010; Cobb-Clark, Salamanca and Zhu, 
2016). However, we consider this method to be problematic, as parents' child-rearing practices respond to actual child behavior. For instance, the parent only restricts the child's choices if the child does not choose what the parent wants. The other way to proxy for parenting style is through parenting values (e.g. Doepke and Zilibotti, 2017: Doepke, Sorrenti and Zilibotti, 2019). We follow this approach and use an additional data source to validate that the parenting values we consider indeed reflect particular child-rearing practices (see Subsection 2.3). We define two parenting values-proxying for the authoritarian and permissive parenting styles-based on a survey question that is similar to the one asked in the World Value Survey (WVS) as used by Doepke and Zilibotti (2017).

First, we define authoritarian parents as those who state that one of the most important qualities that children learn at home is good manners or obedience. We interpret this parenting value as parents' wanting children to conform to societal norms through their behavior. In particular, we hypothesize that parents who value conformity would like their children to conform to the parents' preferences and attitudes. We expect the method for achieving similarity between the parent's and child's preferences to be discipline for these parents, as their values emphasize behavior. Therefore, we refer to parents with this parenting value as authoritarian (but note that this is of course only an approximation of the standard definition of the authoritarian parenting style). Second, we define permissive parents as those who state that one of the most important qualities that children learn at home is imagination. This parenting value stands in stark contrast to the authoritarian value and represents parents who value their children's living out their natural preferences and inclinations. This leaves us with a third group of parents who are neither authoritarian nor permissive. We refer to this remaining group of parents as authoritative. Appendix Table $\mathrm{B}_{5}$ illustrates that compared to authoritarian and permissive parents, authoritative parents value to a much greater extent that the child learns the qualities of responsibility, consideration, tolerance, and, to some extent, independence. Thus, it seems reasonable to refer to this omitted group as authoritative. Thirty-two percent of children have a parent with authoritarian parenting values, while 28 percent of children have a parent with permissive parenting values (Table 1 )

To construct a measure of parental involvement, we rely on parental reports regarding how often the family participated in different types of activities together, with the option of answering at least weekly, monthly, yearly or rarely/never. We rescale the answers to proxy the number of times the family participated in a specific activity within a year and construct a parental involvement index by summing the

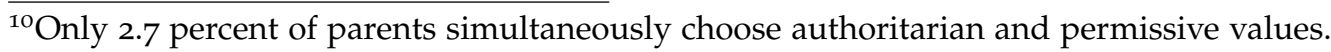


total number of times the family participated in any type of activity together and standardizing it with a mean of zero and a standard deviation of one.

Appendix Table B6 displays correlations between parental patience, parenting values, and parental involvement. Panel A shows the raw correlations between each of the variables, while Panel B conditions on parental background variables similar to our preferred control version in Section 4 . Authoritarian parents are less likely to be patient and they engage in slightly fewer activities with their family ( 4.5 percent of a standard deviation) ${ }^{11}$ Meanwhile, permissive parenting values are uncorrelated with patience and despite a positive, but small, correlation with parental involvement, this correlation is insignificant once controlling for background characteristics. ${ }^{12}$

\subsection{Validation and Replication Sample}

To relate our measures of parenting values to actual parenting practice, we draw on the Danish Longitudinal Survey of Children (DALSC). The survey includes randomly sampled children born between September and October 1995 to a mother with Danish citizenship. It has followed children and their parents throughout childhood and contains very detailed information on parenting practices and parental involvement as reported by mothers and fathers individually.

When their children were four years old, mothers in the DALSC sample answered a question on parenting values that was identical to the question parents in the DLSY sample answered. Moreover, both mothers and fathers answered a question related to parenting values when their child was only six months old. It is therefore unlikely that parents would have adjusted their values to the preferences or behavior of the child. Parents answered on a four-point scale: How important do you find the following qualities are when bringing up children? i) A firm hand, ii) An ability to command the respect of others (instill respect), and iii) An ability to identify oneself with the feelings of the child (empathy with child). We rescale these parenting values from zero to one, with one being very important. To relate parenting values to actual (self-reported) parenting styles, we construct two measures on physical and verbal punishment for each parent (standardized with a mean of zero and a standard deviation of one). These measures are constructed based on questions that each parent answered when the child was age 4,7 , and 11 .

To measure parental involvement in the child's upbringing, we consider two di-

\footnotetext{
${ }^{11}$ Moreover, authoritarian parents are much less likely to be permissive, which, to an extent, is a mechanical relationship, as parents could only choose three values.

${ }^{12}$ These correlation matrices do not differ by parental gender. Yet, mothers are more likely to be authoritarian (not reported).
} 
Table 3

Validation of Parenting Values and Practice

\begin{tabular}{|c|c|c|c|c|}
\hline & \multicolumn{2}{|c|}{ Punishment } & \multicolumn{2}{|c|}{ Quality } \\
\hline & Physical & Verbal & Time & Talking \\
\hline & (1) & $(2)$ & (3) & (4) \\
\hline \multicolumn{5}{|c|}{ Panel A: Maternal values at child age 4 years } \\
\hline Authoritarian & $\begin{array}{c}0.22^{* * *} \\
(0.03)\end{array}$ & $\begin{array}{c}0.13^{* * *} \\
(0.03)\end{array}$ & $\begin{array}{c}-0.09^{* * *} \\
(0.03)\end{array}$ & $\begin{array}{l}-0.03 \\
(0.03)\end{array}$ \\
\hline Permissive & $\begin{array}{l}-0.06^{*} \\
(0.03)\end{array}$ & $\begin{array}{c}-0.08^{* * *} \\
(0.03)\end{array}$ & $\begin{array}{l}0.06^{*} \\
(0.03)\end{array}$ & $\begin{array}{c}0.02 \\
(0.03)\end{array}$ \\
\hline Observations & 5,282 & 5,283 & 5,035 & 5,254 \\
\hline \multicolumn{5}{|c|}{ Panel B: Maternal values at child age 6 months } \\
\hline A Firm Hand $(0-1)$ & $\begin{array}{c}0.22^{* * *} \\
(0.05)\end{array}$ & $\begin{array}{c}0.25^{* * *} \\
(0.05)\end{array}$ & $\begin{array}{l}-0.01 \\
(0.05)\end{array}$ & $\begin{array}{l}-0.02 \\
(0.05)\end{array}$ \\
\hline Instill Respect (0-1) & $\begin{array}{c}0.18^{* * *} \\
(0.06)\end{array}$ & $\begin{array}{l}0.10^{*} \\
(0.06)\end{array}$ & $\begin{array}{l}-0.01 \\
(0.06)\end{array}$ & $\begin{array}{l}0.10^{*} \\
(0.06)\end{array}$ \\
\hline Empathy with Child (o-1) & $\begin{array}{c}-0.44^{* * *} \\
(0.12)\end{array}$ & $\begin{array}{c}-0.39^{* * *} \\
(0.11)\end{array}$ & $\begin{array}{l}0.36^{* * *} \\
(0.12)\end{array}$ & $\begin{array}{l}0.59^{* * *} \\
(0.12)\end{array}$ \\
\hline Observations & 5,059 & 5,059 & 4,860 & 5,035 \\
\hline \multicolumn{5}{|c|}{ Panel C: Paternal values at child age 6 months } \\
\hline A Firm Hand $(0-1)$ & $\begin{array}{c}0.26^{* * *} \\
(0.06)\end{array}$ & $\begin{array}{c}0.03 \\
(0.06)\end{array}$ & $\begin{array}{l}-0.10 \\
(0.06)\end{array}$ & $\begin{array}{l}-0.02 \\
(0.06)\end{array}$ \\
\hline Instill Respect $(0-1)$ & $\begin{array}{c}0.10 \\
(0.07)\end{array}$ & $\begin{array}{l}0.28^{* * *} \\
(0.07)\end{array}$ & $\begin{array}{l}-0.12^{*} \\
(0.07)\end{array}$ & $\begin{array}{c}0.09 \\
(0.07)\end{array}$ \\
\hline Empathy with Child (o-1) & $\begin{array}{c}-0.37^{* * *} \\
(0.10)\end{array}$ & $\begin{array}{l}-0.24^{* *} \\
(0.10)\end{array}$ & $\begin{array}{l}0.44^{* * *} \\
(0.10)\end{array}$ & $\begin{array}{l}0.52^{* * *} \\
(0.10)\end{array}$ \\
\hline Observations & 3,265 & 3,238 & 3,271 & 3,234 \\
\hline
\end{tabular}

Note: Danish Longitudinal Survey of Children (born in 1995). Standard errors in parentheses. ${ }^{*} p<0.1,{ }^{* *} p<0.05,{ }^{* * *} p<0.01$. Each panel-column represents the results from one regression. All models control for mother's and father's length of education and age at childbirth, child gender, birth order, and indicators for size of town of residence at birth, indicators for missing observations on the former controls, and indicators for the number of times the outcome variable was measured. In Panel A, Authoritarian and Permissive are defined as in DLSY; mothers answered this question when child was 4 years old. The parenting values in Panels $B$ and $C$ were asked when the child was 6 months old and are measured on a 4-point scale, rescaled from o (not important at all) to 1 (very important). The dependent variables are standardized (mean $0, \mathrm{SD}_{1}$ ) and measure maternal practice in Panels A and B and paternal practice in Panel C. Maternal punishment is measured at child ages 4, 7, and 11, while paternal punishment is measured at age 7 and 11. Quality Time is measured at the child's age of 7 and 11 for both parents and is the mean of the first component from an principal component analysis at each child age. Quality Talking is measured at age 4, 7 and 11 for mothers and at age 7 and 11 for fathers and is the mean of the first component from an principal component analysis at each child age. 
mensions: quality time spent with the child and quality talking with the child (both measures are standardized with a mean of zero and a standard deviation of one). We construct a Quality Time index as the mean of the first component from a principal component analysis at each child age for each parent and include measures on how often the parent does the following activities with the child when the child is age 7 and 11: help with homework, read/sing, play, do out-of-school activities, and go on an excursion. For the analysis in Subsection 4.4.2, we further split this index into non-educational (play, do out-of-school activities, go on an excursion) and educational quality time (help with homework, read/sing). Similarly, we construct a Quality Talking index as the mean of the first component from a principal component analysis. This index includes measures on how often the parent discusses different aspects of the child's well-being and daily life with the child at age 4, 7, and 11 years.

As expected, parents with authoritarian parenting values (including the proxies thereof in terms of a firm hand and instill respect) tend to be much stricter by using more physical and verbal punishment in the upbringing of their child (Table 3 ). In contrast, parents with permissive parenting values (including empathy with the child) punish their child less compared to authoritative parents (the reference group). Similarly, compared to authoritative parents, authoritarian parents spend less and permissive parents spend more quality time with their child. For quality talking, we only observe increased involvement for parents valuing empathy with the child at age six months. These broad patterns are both observed for mothers and fathers. Thus, parents with different child-rearing values have different parenting practices, especially in terms of the way in which they teach their child how to behave.13

In addition to this validation exercise, we also use the DALSC sample to replicate the moderation analysis in the main sample. The DALSC data do not, however, include our central question. As a coarse proxy for time preferences, we instead use a standardized index measuring impulsivity. ${ }^{14}$ One caveat concerning this measure is that mothers and children were asked the impulsivity questions contemporaneously when the children were 15 years old. In other words, similar to previous studies on the intergenerational correlation of preferences, we cannot rule out the possibility of reverse causality. Moreover, unlike the main sample, we can only say something about the correlations between mothers' and children's preferences. Yet, using the DALSC sample adds two advantageous features to the main analysis. First, it allows

\footnotetext{
${ }^{13}$ Appendix Table $B 7$ further shows correlations between parenting values and maternal educational expectations for the child and splits quality time into educational and non-educational.

${ }^{14}$ Epper et al. (2019a) document a strong and significant association between experimentally elicited patience and survey-measured impulsivity in a representative Danish population data set with 14,191 individuals.
} 
for a replication of intergenerational correlations and its moderators within another domain of time preferences between mothers and children. Second, the DALSC contains much more detailed measures on parental involvement than the DLSY and therefore serves as a robustness check of the specification and measure of parental involvement in the main sample.

\section{Empirical Strategy}

Our empirical analysis centers around the three research questions raised in the introduction: 1) Are time preferences passed on to the next generation? 2) Does such transmission persist or fade out as children age? 3) How relevant is parenting (parenting values and parental involvement) as a socialization device through which preferences carry over from parents to offspring? To answer these questions, we first examine the conditional correlations between parents' and children's preferences by specifying the following linear probability model for the full DLSY sample ${ }^{15}$

$$
\mathrm{T}_{c p g s}=\alpha \mathrm{T}_{p}+Q_{c}^{\prime} \delta+R_{p}^{\prime} \xi+X_{g}^{\prime} \zeta+\theta_{s}+v_{c p g s}
$$

where $c$ denotes the child, $p$ the parent, $g$ the grandparent, and $s$ the school of the surveyed parent. $T$ indicates whether the individual is patient ( 1 ) or not (o). Thus, $\alpha$ represents the intergenerational correlation coefficient of interest. $v_{c p g s}$ denotes the error term; we cluster the standard errors at the parent level to allow for serial correlation in the outcome between siblings.

To shed light on the nature of the intergenerational transmission of patience, we examine these correlations while adding extensive vectors of background characteristics one by one. First, we add a vector of child demographic characteristics, $Q 4^{16}$ that adjusts for potential differences in child patience due to age and gender, among others. Second, we add a vector of parental demographic characteristics, $R$. Third, we include school fixed effects for the surveyed parent's school in 1968, $\theta_{s}$, as this was the original level of sampling. Fourth, to control for differences in parents' SES during their childhood, we add a vector of grandparents' socioeconomic characteristics, $X$. Because parental patience correlates with parents' adult (and children's childhood) SES and because the latter may be a moderator of the intergenerational transmission, we prefer not to control for such variables in this part of the analysis. However, as

\footnotetext{
${ }^{15}$ The results are robust to non-linear specifications; Appendix Figure $\mathrm{B} 4$ illustrates marginal effects from probit models that are similar in magnitude to the ones reported in Table 4.

${ }^{16}$ See Data Appendix A.1.2 for details regarding the exact variables in the various vectors of controls.
} 
a robustness check, we include parental adult socioeconomic controls, child endowments, and child risk preferences.

Second, we test whether the intergenerational transmission of time preferences persists or fades out as children age. We do so by including an interaction term between parental patience and child age. However, as parents' age at first birth is endogenous, it is not possible to say whether a differential transmission by child age in the full sample is due to the persistence (or fade-out) by child age or due to differences in the transmission process between parents who have children at young versus older ages. Therefore, we exploit the fact that most parents have multiple children observed in the sample by further estimating a model comparing siblings. We do this by including parent fixed effects, $\mu_{p}$, thus eliminating potential timeinvariant characteristics within the same sibship. We estimate the sibling model for the total sample of siblings and for the sample of mothers and fathers, separately:

$$
\mathrm{T}_{c p g s}=\phi \mathrm{T}_{p} \times \operatorname{Age}_{c}+\tau \mathrm{Age}_{c}+Q_{c}^{\prime} \delta+\mu_{p}+v_{c p g s},
$$

where $\mathrm{Age}_{c}$ represents child age, normalized by subtracting the mean child age (i.e. 27) to ease the interpretation of $\phi$. As long as we do not omit any important timevarying variables in this model, we can interpret $\phi$ as the causal effect of parental patience on the age gap in child patience. For each parent, we compare siblings born earlier versus later and who are therefore older versus younger at the time of the interview, keeping the parent's age at first birth constant. Consequently, this approach of comparing siblings of the same parent at different ages provides a fruitful setting for studying the persistence of the transmission, while keeping the childhood family environment constant.

Third, we investigate to what extent parenting moderates the transmission of time preferences. For this, the model is:

$$
\mathrm{T}_{\text {cpgs }}=\beta \mathrm{T}_{p}+\mathrm{T}_{p} \times M_{p}^{\prime} \gamma+M_{p}^{\prime} \rho+Q_{c}^{\prime} \delta+R_{p}^{\prime} \xi+X_{g}^{\prime} \zeta+\theta_{s}+v_{c p g s}
$$

where $\mathrm{M}_{p}$ represents the vector of moderators: parenting values (authoritarian and permissive) and parental involvement. From this part of the analysis, we are interested in two sets of estimates. First, we are interested in testing whether the general transmission coefficient, represented by $\beta$, changes in magnitude and statistical significance once we allow for a differential transmission from parents to children by the family socialization process. In the specification including both parenting dimensions, $\beta$ represents the transmission of patience from authoritative parents with average parental involvement. Second, we are interested in estimating the moderat- 
ing role of the two aspects of parenting for the transmission process, represented by the vector of estimates in $\gamma$. In other words, this part of the analysis examines potential heterogeneity in the intergenerational transmission of patience by different styles of parenting (values and involvement). This will help shed light on the moderators of the preference propagation process.

\section{Results}

\section{I Do Parents Transmit Patience to Children?}

The main finding in Table 4 is that parents significantly transmit patience to their children and that this transmission is robust to the inclusion of comprehensive sets of controls. Column (1) shows the raw correlation between parental and child patience: patient parents are 8.1 percentage points more likely to have a patient child compared to impatient parents ${ }^{17}$ Once controlling for child demographic characteristics (column (2)), the estimated transmission coefficient decreases slightly due to the correlation between parental patience and age at childbirth (Appendix Table $\mathrm{B}_{4}$ ) and the empirical pattern of patience by child age (Appendix Figure $B 1$. ${ }^{18}$ It is noteworthy that the magnitude of the intergenerational transmission remains similar when further adding parental demographic variables, parents' school fixed effects (column (3)), and a rich set of grandparental socioeconomic characteristics (column (4)).

The control version in column (4) represents our preferred model, as it includes comprehensive sets of controls predetermined at the time of the elicitation of parental time preferences. This model suggests that children of patient parents are 7.1 percentage points more likely to be patient themselves; this corresponds to an increased probability of 12.1 percent relative to the mean of children with impatient parents ${ }^{19}$ Considering this estimate differently, it also implies that children of impatient parents are 21.5 percent more likely to be impatient compared to children of patient parents. It is remarkable to observe such a strong transmission of patience from parents to children in this setting with a time lag of four decades between the elicitation of parents' and children's preferences 20

17The strength of the intergenerational correlation coefficient does not differ by parent gender in any of the models (not reported).

${ }^{18}$ The decreased magnitude of the transmission estimate is driven by the inclusion of child age controls (not reported).

${ }^{19}$ The probability that the child is patient (impatient) among children of impatient (patient) parents is 58.8 (33.1) percent.

${ }^{20}$ In the sample, 62 child-parent pairs ( 2 percent of our sample) are not biologically related. If we include an indicator for a non-biological relationship and an interaction term between this variable 
Table 4

Intergenerational Transmission of Patience

\section{Dependent Variable: Child is Patient}

(1)

$$
\text { (2) }
$$

(3)

(4)

(5)

(5) (6)

(6) (7)

\begin{tabular}{|c|c|c|c|c|c|c|c|}
\hline Parent is Patient & $\begin{array}{c}0.081^{* * *} \\
(0.021)\end{array}$ & $\begin{array}{c}0.068^{* * *} \\
(0.020)\end{array}$ & $\begin{array}{c}0.071^{* * *} \\
(0.021)\end{array}$ & $\begin{array}{c}0.071^{* * *} \\
(0.021)\end{array}$ & $\begin{array}{l}0.051^{* *} \\
(0.021)\end{array}$ & $\begin{array}{c}0.073^{* * *} \\
(0.022)\end{array}$ & $\begin{array}{c}0.067^{* * *} \\
(0.026)\end{array}$ \\
\hline Sample & All & All & All & All & All & $1974^{+}$ & $1978+$ \\
\hline Child demogra. & & $\checkmark$ & $\checkmark$ & $\checkmark$ & $\checkmark$ & $\checkmark$ & $\checkmark$ \\
\hline Parent demogra. & & & $\checkmark$ & $\checkmark$ & $\checkmark$ & $\checkmark$ & $\checkmark$ \\
\hline Parent School FE & & & $\checkmark$ & $\checkmark$ & $\checkmark$ & $\checkmark$ & $\checkmark$ \\
\hline Grandparent SES & & & & $\checkmark$ & $\checkmark$ & $\checkmark$ & $\checkmark$ \\
\hline Parent SES & & & & & $\checkmark$ & & \\
\hline Child endowm. & & & & & $\checkmark$ & & \\
\hline Child risk pref & & & & & $\checkmark$ & & \\
\hline Observations & 3,101 & 3,101 & 3,101 & 3,101 & 3,101 & 3,014 & 2,197 \\
\hline Average of $T_{c}$ & 0.648 & 0.648 & 0.648 & 0.648 & 0.648 & 0.653 & 0.686 \\
\hline
\end{tabular}

Note: Standard errors in parentheses, clustered at the parent level. ${ }^{*} p<0.1,{ }^{* *} p<0.05,{ }^{* * *} p<0.01$. The outcome variable indicates whether the child is patient (1) or not (o). Each column presents the results from separate regressions. Each model is estimated as a linear probability model. All represents the full sample of children. The samples $1974+$ and $1978+$ only include, respectively, children born after 1973 and children whose surveyed parent had their first child after 1977. Column (1) also controls for parent gender. Child demographics includes five-year age interval dummies, birth order dummies, and an indicator for a being twin. Parent demographics includes indicators for being born before 1954, being born after 1954, being female, the child-parent gender combination, and birth order. Parent School FE includes fixed effects for the surveyed parent's school in 1968. Grandparent SES includes grand-parental attitudes towards child education and work, an index for the grandparents' educational investment in the parent, quadratic taxable income in 1967 reported by the tax authorities, quadratic number of grandparents' children, indicators for the grandmaternal/paternal level of education, vocational training/education, whether the grandmother/grandfather has work subordinates, grandmother is housewife, gender of the surveyed grandparent, the parent lives with both parents at age 14, and indicators for missing observations for the different control variables. Parent SES includes the surveyed parent's spatial, verbal, and inductive abilities measured at age 14, the mother's and father's length of education, cumulative work experience through 2004, cumulative length of unemployment through 2004, the natural logarithm of average annual labor earnings 1980-2004, quadratic number of children, indicators for the child living with both parents at age 16, the mother/father has children with a person other than the parent, and missing observations for the different control variables. Child endowments include squared birth weight, child IQ, standardized length of highest completed education by 2016 by cohort, and indicators for being born preterm and missing observations for the different control variables. 
Column (5) provides additional sets of controls to compare children with similar health endowments, skills, and risk references, who grow up in similar family environments. This is not our preferred model because parental patience clearly influences children's socioeconomic family environment and might also influence child characteristics. Therefore, including these controls might absorb some of the variation in the transmission process. Put differently, we would expect that the inclusion of these additional, broad sets of controls would cause the estimated correlation coefficient to decrease in magnitude ${ }^{21}$ This is also what we see in model (5); the estimate is smaller in magnitude than the one in our preferred model. Yet, it illustrates that even when conditioning on a detailed set of characteristics in the family environment that are influenced by parental patience, we still observe a sizable intergenerational transmission of time preferences (with an estimate of 5.1 percentage points). This finding is consistent with the results in Chowdhury, Sutter and Zimmermann (2018), indicating that the transmission of time preferences is independent of SES. Moreover, as discussed in Section 2, risk preferences might be associated with our measure of time preferences and thereby influence the estimated transmission of patience. The result in model (5) therefore also suggests that risk preferences are not an important confounding factor influencing our results on patience propagation. ${ }^{22}$

As mentioned previously, only 2.8 percent of children were already born when parents answered the time preference question. However, including those children in the analysis could be problematic, as having a child may affect revealed patience. To test for this possibility, column (6) replicates our preferred model while restricting the sample to those children born after the elicitation of parents' preferences. The results are robust to this restriction. Moreover, a concern with our measure could be that parents who planned to have children in the near future might have preferred the flat (impatient) wage profile simply to be able to afford having children and not because they were truly impatient. Therefore, column (7) excludes parents (and their children) who had their first child before the patient wage profile would have been fully implemented (i.e. before 1978). The results are again insensitive to this restriction, suggesting that our time preference measure is not just capturing correlations between parents' and children's fertility preferences.

and parental patience, the estimate of the interaction term is positive but far from significant, possibly due to the small sample of non-biological links. The estimate is 0.044 ( $s e=0.121$; $p$-value $=.714$ ). Consequently, in our data, there is no evidence for genetic transmission of patience, although we do not have the power to draw any strong conclusion. See also footnote 6

${ }^{21}$ This is similar to the bad control problem. We do not claim, however, that our estimated transmission of patience is causal, as we do not have exogeneity in parental preferences.

${ }^{22}$ If we only add risk preference controls to model (4), the estimate is $0.067(s e=0.021)$. 


\subsection{Does the Transmission Persist?}

\begin{tabular}{|c|c|c|c|c|}
\hline & \multicolumn{4}{|c|}{ Dependent Variable: Child is Patient } \\
\hline & (1) & $(2)$ & (3) & (4) \\
\hline Parent is Patient & $\begin{array}{c}0.071^{* * *} \\
(0.021)\end{array}$ & & & \\
\hline Parent is Patient $\times$ Age & $\begin{array}{l}-0.002 \\
(0.003)\end{array}$ & $\begin{array}{c}0.000 \\
(0.008)\end{array}$ & $\begin{array}{l}-0.011 \\
(0.011)\end{array}$ & $\begin{array}{l}0.019^{*} \\
(0.011)\end{array}$ \\
\hline Sample & All & Siblings & Mothers & Fathers \\
\hline Observations & 3,101 & 2,255 & 1,170 & 1,085 \\
\hline Average of $T_{\mathcal{C}}$ & 0.648 & 0.647 & 0.610 & 0.686 \\
\hline
\end{tabular}

Note: Standard errors in parentheses, clustered at the parent level. ${ }^{*} p<0.1,{ }^{* *}$ $p<0.05,{ }^{* * *} p<0.01$. The outcome variable indicates whether the child is patient (1) or not (o). Each column presents the results from separate regressions. Each model is estimated as a linear probability model. All represents the full sample of children. The samples Siblings, Mothers, and Fathers only include, respectively, children with at least one sibling in the sample, siblings for whom the sampled parent is the mother, and siblings for whom the sampled parent is the father. Columns ( 1 ) controls for Child demographics, Parent demographics, Parent School FE, and Grandparent SES. Columns (2) to (4) control for Child demographics and parent fixed effects. Age is normalized by subtracting the mean child age (27 years), such that its mean is $\mathrm{o}$ and is controlled for in all models.

To examine the permanence of the intergenerational transmission, we explore whether the intergenerational correlation differs by child age. Column (1) in Table 5 estimates our preferred model but now also includes an interaction term between parental patience and child normalized age. The estimate of the interaction term shows that the transmission of patience from parents to children does not vary by child age, suggesting that the preference propagation persists as children age. Yet, as discussed in Section 3 . this result is not necessarily due to a lack of fade-out by age, but could be explained by a stronger transmission of patience among parents who have children at younger ages followed by some fade-out. Therefore, column (2) restricts the sample to siblings and includes parent fixed effects. ${ }^{23}$ Comparing siblings with each other clearly shows that parents do not differentially transmit patience to younger versus older children or vice versa. As average spacing between the oldest and youngest sibling within a family in the sample is 5.8 years $(s d=3.9)$; this of course does not tell whether the strength of the transmission is completely constant across all ages. However, it suggests that the influence of parents' preferences on ${ }^{23}$ The results for columns (2)-(4) are similar when restricting the sample to full siblings (not reported). 
children's preferences persists. The remaining two models split the sample by parent gender and show that, if anything, fathers tend to affect older children more strongly relative to younger siblings. Consequently, these findings emphasize the persistence of the transmission effect, stressing that it does not fade out with child age.

\subsection{Heterogeneity by Parenting?}

So far, we have documented a significant and robust correlation in patience across generations and have shown that this transmission persists as children age. This part of the analysis investigates the extent to which parenting moderates the intergeneration transmission of patience. All models in Table 6 control for the large set of covariates included in our preferred model (column (4) in Table 4). Column (1) replicates our preferred model in the sample of parents answering the parenting value question.

Column (2) includes parenting values and their interactions with parental patience; column (3) replicates this specification for the sample with an observation on parental involvement. From the non-interacted estimates of parenting values, it is clear that both authoritarian and permissive parents, on average, have less-patient children. As expected, this also implies that authoritative parents (the omitted category) have more-patient children. The estimates of the interactions show that authoritarian and permissive parents are in fact those who drive the transmission of time preferences. Thus, authoritarian parents seem, to a large extent, successful in terms of socializing their children to conform to their own (the parents') preferences. The fact that we observe a similar degree of patience transmission between authoritarian and permissive parents could be because children left to follow their own natural preferences and inclinations tend to imitate their parents. At the same time, authoritative parents do not transmit their time preferences to children. Interpreted through the lens of Doepke and Zilibotti (2017), this finding suggests that authoritative parents indeed manage to mold their child's time preferences to reach an outcome that is conducive to success in life (patience), regardless of the parents' own time preferences.

To test whether parental involvement moderates the intergenerational transmission of patience, column (4) includes parental patience interacted with these aspects of family socialization. This model suggests that involvement is not an important moderator, as the estimated interaction term is very close to zero and is not statistically significant. Next, column (5) simultaneously includes both dimensions of parenting and their interactions with parental patience. The results from this model confirm the previous findings that parenting values are important dimensions for 
Table 6

Intergenerational Transmission of Patience: Heterogeneity by Parenting Values and Parental Involvement

\begin{tabular}{|c|c|c|c|c|c|c|}
\hline & \multicolumn{6}{|c|}{ Dependent Variable: Child is Patient $\left(T_{\mathcal{c}}\right)$} \\
\hline & (1) & (2) & (3) & (4) & (5) & (6) \\
\hline Parent is Patient $\left(T_{p}\right)$ & $\begin{array}{c}0.085^{* * *} \\
(0.022)\end{array}$ & $\begin{array}{c}-0.021 \\
(0.031)\end{array}$ & $\begin{array}{c}-0.013 \\
(0.038)\end{array}$ & $\begin{array}{c}0.094^{* * *} \\
(0.026)\end{array}$ & $\begin{array}{c}-0.007 \\
(0.038)\end{array}$ & $\begin{array}{l}-0.009 \\
(0.026)\end{array}$ \\
\hline$T_{p} \times$ Authoritarian $(\mathrm{A})$ & & $\begin{array}{c}0.171^{* * *} \\
(0.045)\end{array}$ & $\begin{array}{l}0.168^{* * *} \\
(0.054)\end{array}$ & & $\begin{array}{c}0.154^{* * *} \\
(0.054)\end{array}$ & $\begin{array}{c}0.157^{* * *} \\
(0.053)\end{array}$ \\
\hline$T_{p} \times$ Permissive $(\mathrm{P})$ & & $\begin{array}{c}0.141^{* * *} \\
(0.049)\end{array}$ & $\begin{array}{l}0.142^{* *} \\
(0.057)\end{array}$ & & $\begin{array}{l}0.134^{* *} \\
(0.056)\end{array}$ & $\begin{array}{l}0.140^{* *} \\
(0.057)\end{array}$ \\
\hline$T_{p} \times$ Involvement & & & & $\begin{array}{c}0.007 \\
(0.027)\end{array}$ & $\begin{array}{c}0.011 \\
(0.026)\end{array}$ & $\begin{array}{c}0.036 \\
(0.037)\end{array}$ \\
\hline$T_{p} \times \mathrm{A} \times$ Involvement & & & & & & $\begin{array}{l}-0.011 \\
(0.056)\end{array}$ \\
\hline$T_{p} \times \mathrm{P} \times$ Involvement & & & & & & $\begin{array}{l}-0.066 \\
\text { (0.061) }\end{array}$ \\
\hline Authoritarian & & $\begin{array}{c}-0.185^{* * *} \\
(0.039)\end{array}$ & $\begin{array}{c}-0.189^{* * *} \\
(0.047)\end{array}$ & & $\begin{array}{c}-0.177^{* * *} \\
(0.047)\end{array}$ & $\begin{array}{c}-0.179^{* * *} \\
(0.047)\end{array}$ \\
\hline Permissive & & $\begin{array}{l}-0.101^{* *} \\
(0.044)\end{array}$ & $\begin{array}{c}-0.096^{*} \\
(0.052)\end{array}$ & & $\begin{array}{l}-0.088^{*} \\
(0.051)\end{array}$ & $\begin{array}{l}-0.092^{*} \\
(0.051)\end{array}$ \\
\hline Involvement & & & & $\begin{array}{c}0.029 \\
(0.024)\end{array}$ & $\begin{array}{c}0.023 \\
(0.023)\end{array}$ & $\begin{array}{l}-0.001 \\
(0.033)\end{array}$ \\
\hline $\mathrm{A} \times$ Involvement & & & & & & $\begin{array}{c}0.034 \\
(0.049)\end{array}$ \\
\hline $\mathrm{P} \times$ Involvement & & & & & & $\begin{array}{c}0.037 \\
(0.055)\end{array}$ \\
\hline Observations & 2859 & 2859 & 2132 & 2132 & 2132 & 2132 \\
\hline Average of $T_{\mathcal{C}}$ & 0.645 & 0.645 & 0.657 & 0.657 & 0.657 & 0.657 \\
\hline
\end{tabular}

Note: Standard errors in parentheses, clustered at the parent level. ${ }^{*} p<0.1,{ }^{* *} p<0.05,{ }^{* * *} p<0.01$. The outcome variable indicates whether the child is patient (1) or not (o). Each model is estimated as a linear probability model. Each column presents the results from separate regressions. All models control for Child demographics, Parent demographics, Parent School FE, and Grandparent SES. 
heterogeneity in the transmission of patience, while involvement is not. Finally, column (6) further interacts parenting values with parental involvement and parental patience. Such interaction effects do not seem to be important for patience propagation. Consequently, the main finding from this moderation analysis is that parenting values, in contrast to parental involvement, are important moderators of the socialization process. This clearly provides new insights into the black box of family socialization.

We find some relevant differences by parental gender (Appendix Table B8) 24 While authoritarian parenting values are the strongest moderator of mothers' preference transmission, permissive values have greater predictive power as moderators for fathers' propagation of patience 25 Moreover, some relevant differences emerge in terms of the moderating role of involvement. Similar to the findings in Alan et al. (2017), we find that mothers with greater involvement more strongly transmit their preferences to children. As Alan et al. (2017) suggest, this might be because children who spend more time with their mothers have a greater opportunity to observe and imitate maternal behavior. In contrast, more-involved fathers tend to transmit patience to their children less strongly. This difference by parental gender is likely due to the different roles mothers and fathers play in the upbringing of children. Fathers who display greater involvement with their children might also make more effort to develop more favorable outcomes in their children.

\subsection{Robustness of Moderation Results}

\subsubsection{SES as an Alternative Moderator?}

Given a correlation between parenting values and parental SES (Appendix Table B6), one concern regarding the interpretation of the heterogeneity results is that SES might indeed be a more relevant moderator than parenting values. For instance, in light of the model by Bisin and Verdier (2001), parents of higher SES might have a stronger degree of paternalistic altruism (imperfect empathy) and therefore exhibit weaker transmission of preferences to their offspring. Table 7 tests the relevance of SES as a moderator of the intergenerational transmission of patience, using the SES index. From this, it is clear that childhood SES does not moderate the transmission process.

Including the SES index and its interaction with parental patience in the main

\footnotetext{
${ }^{24}$ In contrast, we find no significant difference in the moderation patterns by child gender (not shown). The sample size is too small to meaningfully consider differences by child-parent gender combinations.

${ }^{25}$ However, we cannot rule out that the magnitude of the interaction terms between parental patience and authoritarian and permissive values, respectively, are not statistically different.
} 
Table 7

Intergenerational Transmission of Patience: Heterogeneity by SES

\begin{tabular}{lccccc}
\hline & \multicolumn{5}{c}{ Dependent Variable: Child is Patient $\left(T_{c}\right)$} \\
& $(1)$ & $(2)$ & $(3)$ & $(4)$ & $(5)$ \\
\hline Parent is Patient $\left(T_{p}\right)$ & $0.064^{* * *}$ & $0.064^{* * *}$ & -0.031 & -0.020 & -0.014 \\
& $(0.021)$ & $(0.021)$ & $(0.031)$ & $(0.038)$ & $(0.038)$ \\
$T_{p} \times$ SES index & 0.002 & & 0.003 & 0.008 & \\
& $(0.022)$ & & $(0.024)$ & $(0.030)$ & \\
$T_{p} \times$ Parental Edu & & -0.004 & & & 0.010 \\
& & $(0.021)$ & & & $(0.029)$ \\
$T_{p} \times$ Authoritarian & & & $0.172^{* * *}$ & $0.160^{* * *}$ & $0.159^{* * *}$ \\
& & & $(0.045)$ & $(0.054)$ & $(0.055)$ \\
$T_{p} \times$ Permissive & & & $0.146^{* * *}$ & $0.141^{* *}$ & $0.132^{* *}$ \\
& & & $(0.049)$ & $(0.056)$ & $(0.058)$ \\
$T_{p} \times$ Involvement & & & & 0.011 & 0.011 \\
& & & & $(0.026)$ & $(0.026)$ \\
Observations & 3101 & 3101 & 2859 & 2132 & 2132 \\
Average of $T_{c}$ & 0.648 & 0.648 & 0.645 & 0.657 & 0.657 \\
\hline
\end{tabular}

Note: Standard errors in parentheses, clustered at the parent level. ${ }^{*} p<0.1,{ }^{* *} p<0.05$, *** $p<0.01$. The outcome variable indicates whether the child is patient (1) or not (o). Each model is estimated as a linear probability model. Each column presents the results from separate regressions. All models control for Child demographics, Parent demographics, Parent School FE, and Grandparent SES. Each model controls for the moderators that are interacted with $T_{p}$. 
model illustrates the absence of any relevant moderating role of the socioeconomic childhood family environment (column (1)), with a precisely estimated zero. As an alternative measure of SES, column (2) interacts average parental education with parental patience instead of the SES index. We do this because parental education is the only socioeconomic variable that has some (albeit small) predictive power in terms of predicting child patience. From this, we still do not find that the socioeconomic environment moderates the preference propagation. Further, including simultaneous interactions between parental patience and SES, parenting values, as well as parental involvement does not change the previous results. In other words, SES and parental involvement do not represent relevant margins for heterogeneity in the patience transmission, while parenting values do. Consequently, the heterogeneity results with respect to parenting are robust to the inclusion of SES as an alternative dimension of family socialization.

\subsubsection{Replication in the DALSC Sample}

The analysis so far, relying on the DLSY, has demonstrated that parents transmit patience to their offspring and that parenting values are important moderators of the relationship. The purpose of this analysis is twofold: 1) to replicate the main findings on moderators in a different sample with a different measure of time preferences (impulsivity) and 2) to test the robustness of the findings for involvement when having richer data on this aspect of parents' socialization with their children. Using the DALSC sample, column (1) in Table 8 replicates the finding in Table 4 of an intergenerational correlation in preferences. ${ }^{26}$

Having a mother scoring one standard deviation higher in the impulsivity index increases child impulsivity by 12 percent of a standard deviation. The magnitude of the correlation coefficient is comparable to the correlation between mothers' and children's risk preferences in Dohmen et al. (2012) (14.9 percent of a standard deviation). The intergenerational correlation between mothers' and children's impulsivity is much stronger for mothers with authoritarian values (column (2)). This is consistent with the gender-specific findings in Appendix Table B8. Using a richer measure of quality time than that used in the main analysis confirms the previous result that maternal involvement does not moderate the preference correlation (column (3)). However, when splitting involvement into non-educational and educational quality time, the estimates indicate that non-educational quality time additionally moderates some of the transmission (columns (4)-(6)). This result is again in line with

\footnotetext{
${ }^{26}$ All results in Table 8 are robust to the inclusion of paternal quality time variables, maternal personality traits, and maternal and child IQ (not shown).
} 
Table 8

Replication in DALSC Sample: Heterogeneity in the Intergenerational Transmission of Impulsivity

\begin{tabular}{|c|c|c|c|c|c|c|}
\hline & \multicolumn{6}{|c|}{ Dependent Variable: Child Impulsivity (standardized) } \\
\hline & $(1)$ & (2) & (3) & (4) & (5) & $(6)$ \\
\hline Mother impulsivity $\left(I_{m}\right)$ & $\begin{array}{l}0.12^{* * *} \\
(0.02)\end{array}$ & $\begin{array}{l}0.08^{* * *} \\
(0.03)\end{array}$ & $\begin{array}{l}0.07^{* * *} \\
(0.03)\end{array}$ & $\begin{array}{l}0.07^{* * *} \\
(0.03)\end{array}$ & $\begin{array}{l}0.07^{* * *} \\
(0.03)\end{array}$ & $\begin{array}{l}0.07^{* * *} \\
(0.03)\end{array}$ \\
\hline$I_{m} \times$ Authoritarian & & $\begin{array}{l}0.08^{* *} \\
(0.03)\end{array}$ & $\begin{array}{l}0.08^{* *} \\
(0.04)\end{array}$ & $\begin{array}{l}0.08^{* *} \\
(0.04)\end{array}$ & $\begin{array}{l}0.08^{* *} \\
(0.04)\end{array}$ & $\begin{array}{l}0.08^{* *} \\
(0.04)\end{array}$ \\
\hline$I_{m} \times$ Permissive & & $\begin{array}{c}0.03 \\
(0.04)\end{array}$ & $\begin{array}{c}0.03 \\
(0.04)\end{array}$ & $\begin{array}{c}0.03 \\
(0.04)\end{array}$ & $\begin{array}{c}0.03 \\
(0.04)\end{array}$ & $\begin{array}{c}0.03 \\
(0.04)\end{array}$ \\
\hline$I_{m} \times$ Quality Time & & & $\begin{array}{c}0.02 \\
(0.02)\end{array}$ & & & \\
\hline$I_{m} \times$ Non-Ed Quality Time & & & & $\begin{array}{l}0.03^{* *} \\
(0.02)\end{array}$ & $\begin{array}{c}0.03 \\
(0.02)\end{array}$ & $\begin{array}{l}0.03^{*} \\
(0.02)\end{array}$ \\
\hline$I_{m} \times$ Ed Quality Time & & & & $\begin{array}{l}-0.02 \\
(0.02)\end{array}$ & $\begin{array}{l}-0.02 \\
(0.02)\end{array}$ & $\begin{array}{l}-0.02 \\
(0.02)\end{array}$ \\
\hline$I_{m} \times$ Quality Talking & & & & & $\begin{array}{c}0.03 \\
(0.02)\end{array}$ & $\begin{array}{c}0.03 \\
(0.02)\end{array}$ \\
\hline$I_{m} \times$ Avg Parental Educ & & & & & & $\begin{array}{l}-0.00 \\
(0.02)\end{array}$ \\
\hline Observations & 3,833 & 3,833 & 3,767 & 3,767 & 3,767 & 3,767 \\
\hline $\begin{array}{l}\text { Note: Danish Longitudinal Survey of } \\
p<0.01 \text {. The outcome variable is a c } \\
\text { deviation of one. Each column represe } \\
\text { of education and age at childbirth, ch } \\
\text { missing observations on the former co } \\
\text { model were measured. Quality Time i } \\
\text { including how often the mother does } \\
\text { activities, go on an excursion, help w } \\
\text { similarly, including play, do out-of-sch } \\
\text { the mean of the standardized first com } \\
\text { the following with the child at age } 4,7 \text {, } \\
\text { activities at kindergarten/day-care (4); } \\
\text { other children (4/7/11); relationship to } \\
\text { wellbeing. }\end{array}$ & $\begin{array}{l}\text { gender, bi } \\
\text { ols, and in } \\
\text { he mean of } \\
\text { ne followin } \\
\text { n homewor } \\
\text { lactivities } \\
\text { nent from }\end{array}$ & $\begin{array}{l}\text { 1995). St } \\
\text { of child im } \\
\text { m one regr } \\
\text { order, indi } \\
\text { tors for the } \\
\text { standardi } \\
\text { tivities wit } \\
\text { nd read/si } \\
\text { on an excu } \\
\text { ncipal com }\end{array}$ & $\begin{array}{l}\text { dard error } \\
\text { lsivity, sta } \\
\text { ion. All n } \\
\text { ors for siz } \\
\text { mber of } \\
\text { f first com } \\
\text { the child } \\
\text { Non-Ed } \\
\text { on (help } \\
\text { nent anal }\end{array}$ & $\begin{array}{l}\text { parenthes } \\
\text { dized wit } \\
\text { s control } \\
\text { town of r } \\
\text { the qualit } \\
\text { ent from a } \\
\text { e } 7 \text { and } 1 \\
\text { ity Time } \\
\text { homewor } \\
\text { ncluding }\end{array}$ & $\begin{array}{l}p<0.1 \text {, } \\
\text { nean of zer } \\
\text { other's and } \\
\text { nce at birth } \\
\text { evariables } \\
\text { cipal comp } \\
\text { ars: play, } \\
\text { uality Time } \\
\text { d/sing). } \\
\text { often the m } \\
\text { the }\end{array}$ & $\begin{array}{l}p<0.05, * * \\
\text { and standarc } \\
\text { ather's lengtt } \\
\text { indicators fo } \\
\text { acluded in the } \\
\text { nent analysis } \\
\text { out-of-schoo } \\
\text { is constructec } \\
\text { ality Talking ise } \\
\text { ther discusse } \\
\text { hild's plannec } \\
\text { elationship to }\end{array}$ \\
\hline
\end{tabular}


the gender-specific findings in the DLSY sample, for which the involvement measure mainly includes non-educational activities. At the same time, quality talking does not moderate the transmission. Finally, parental education does not moderate the relationship either. Consequently, all the main findings in the DLSY sample replicate in the DALSC sample, when using better measures on maternal involvement and when using a different time preference measure.

\section{Concluding Remarks}

We study the intergenerational transmission of time preferences in a broad and heterogeneous population using an internally and externally validated survey measure. Parental and offspring patience were elicited four decades apart, thereby eliminating concerns regarding reverse causality. We document that the transmission of patience across generations is both substantial and robust. Children with patient parents are 7 to 8 percentage points more likely to also be patient. Moreover, the transmission is insensitive to the inclusion of a comprehensive set of administratively reported controls, and the size of the transmission coefficient does not diminish as children age.

We further open up the black box of family socialization by considering two theoretically relevant moderators of the transmission process. Specifically, we explore the moderating roles of parenting values and parental involvement in patience propagation. We find that authoritarian and permissive parents transmit patience to their children, while authoritative parents do not. Interestingly, more parental time investment does not contribute to the patience transmission, suggesting that style is more important than the time shared in joint activities with children. Moreover, we show that these findings are robust to the inclusion of a third potentially relevant dimension of socialization, namely, SES. We further replicate these findings in another independent survey. This latter survey also permits us to validate parenting values with self-reported parenting behaviors. Specifically, we show that parents who report authoritarian values indeed implement stricter parenting practices, such as more physical and verbal punishment, and that the opposite is true for parents reporting permissive parenting values.

Despite the unique setup of our study and the rich controls we employ, our study faces some limitations. We see three directions that require further exploration for a better understanding of the mechanisms behind economic preference propagation. First, our study does not permit establishing a causal link between parenting style, parental patience, and offspring patience. Demonstrating such a link would require 
some form of random assignment of children to parents-for instance, by exploiting orphan status or adoptions-and exogenous changes in parenting style. For obvious reasons, such a setup would pose different challenges. Children's time preferences may, for instance, be affected by emotional and financial shocks they experience during childhood. Moreover, programs that affect parenting style might well influence other dimensions of the family socialization process, other than purely the parents' way of parenting.

Second, and linked to our first point, we believe that genetic factors as a moderator of preference transmission deserve further attention. Most work has been devoted to the genetic origins of risk and social preferences (see e.g. Linnér et al., 2019). For time preferences, however, this issue still remains underresearched. A notable exception is Benjamin et al. (2012), who conclude that there is significant genetic transmission of patience, albeit the estimated heritabilities of genotyped single nucloid polymorphisms (SNPs) are consistently lower than twin-based estimates suggest. This research is complementary to ours; it provides important insights regarding genetic transmission, but disregards the many faceted roles of socialization. Future studies tackling the question of patience transmission may thus simultaneously investigate the roles of fixed (genetic) and changeable (nurturing) factors and decompose the observed variation of this trait into genetic and socialization components. Third, it is not fully clear how well self-reported parenting values and practices reflect actual parenting styles. To answer this question, it would be helpful to gather third-party information on parenting style. This could be achieved, for example, by interviewing parents' peers.

Our findings have a number of important implications. First, our transmission results and the fact that individual time preferences are highly predictive of peoples' real world economic outcomes suggest an explanation for the cross-generational correlation of economic outcomes. Therefore, the transmission channel may also help us better understand sources of economic inequality and the varying degrees of social mobility observed across different communities within the same country as well as across countries (e.g. Chetty et al., 2014, Corak, 2013). Second, macroeconomic models considering multiple generations usually assume that time preferences propagate from parents to offspring (see e.g. Krusell and Smith, 1998). The empirical evidence on the intergenerational transmission of preferences, however, has previously only considered relatively short time horizons. Our study provides support for the assumption in macroeconomic models that time preferences indeed transmit from generation to generation and that this propagation persists over a very long time period. 


\section{References}

Agostinelli, Francesco, and Giuseppe Sorrenti. 2018. "Money vs. Time: Family Income, Maternal Labor Supply, and Child Development." University of Zurich, Department of Economics, Working Paper.

Alan, Sule, and Seda Ertac. 2018. "Fostering Patience in the Classroom: Results from Randomized Educational Intervention." Journal of Political Economy, 126(5): 18651911.

Alan, Sule, Nazli Baydar, Teodora Boneva, Thomas F. Crossley, and Seda Ertac. 2017. "Transmission of Risk Preferences from Mothers to Daughters." Journal of Economic Behavior and Organization, 134: 60-77.

Andreoni, James, Michael A. Kuhn, John A. List, Anya Samek, Kevin Sokal, and Charles Sprenger. 2019. "Toward an Understanding of the Development of Time Preferences: Evidence from Field Experiments." Journal of Public Economics, 177.

Andreoni, James, Michael Kuhn, John A. List, Anya Samek, and Charles Sprenger. 2017. "Field Experiments on the Development of Time Preferences." Working Paper.

Attanasio, Orazio, Sarah Cattan, Emla Fitzsimons, Costas Meghir, and Marta Rubio-Codina. 2019. "Estimating the Production Function for Human Capital: Results from a Randomized Control Trial in Colombia." American Economic Review.

Attema, Arthur E., Han Bleichrodt, Yu Gao, Zhenxing Huang, and Peter P Wakker. 2016. "Measuring Discounting Without Measuring Utility." American Economic Review, 106(6): 1476-94.

Ayduk, Ozlem, Rodolfo Mendoza-Denton, Walter Mischel, Geraldine Downey, Philip K. Peake, and Monica Rodriguez. 200o. "Regulating the Interpersonal Self: Strategic Self-regulation for Coping With Rejection Sensitivity." Journal of Personality and Social Psychology, 79(5): 776-792.

Bartling, Björn, Ernst Fehr, Barbara Fischer, Fabian Kosse, Michel Maréchal, Friedhelm Pfeiffer, Daniel Schunk, Jürgen Schupp, C. Katharina Spieß, and Gert G Wagner. 2010. "Determinanten Kindlicher Geduld - Ergebnisse einer Experimentalstudie im Haushaltskontext." Schmollers Jahrbuch, 130(3): 297-323.

Baumrind, Diana. 1967. "Child Care Practices Anteceding Three Patterns of Preschool Behavior." Genetic Psychology Monographs.

Benjamin, Daniel J., David Cesarini, Matthijs JHM Van Der Loos, Christopher T. Dawes, Philipp D. Koellinger, Patrik KE Magnusson, Christopher F. Chabris, Dalton Conley, David Laibson, Magnus Johannesson, et al. 2012. "The Genetic Architecture of Economic and Political Preferences." Proceedings of the National Academy of Sciences, 109(21): 8026-8031.

Bisin, Alberto, and Thierry Verdier. 2001. "The Economics of Cultural Transmission and the Dynamics of Preferences." Journal of Economic Theory, 97(2): 298-319. 
Bono, Emilia Del, Marco Francesconi, Yvonne Kelly, and Amanda Sacker. 2016. "Early Maternal Time Investment and Early Child Outcomes." Economic Journal, 126(596): F96-F135.

Brown, Heather, and Marjon van der Pol. 2015. "Intergenerational Transfer of Time and Risk Preferences." Journal of Economic Psychology, 49: 187-204.

Cappelen, Alexander W., John A. List, Anya Samek, and Bertil Tungodden. 2019. "The Effect of Early Education on Social Preferences." Journal of Political Economy.

Cesarini, David, Christopher T. Dawes, Magnus Johannesson, Paul Lichtenstein, and Björn Wallace. 2009. "Genetic Variation in Preferences for Giving and Risk Taking." Quarterly Journal of Economics, 124(2): 809-842.

Chabris, Christopher F., David Laibson, Charlie L. Morris, Jonathon P. Schuldt, and Dmitry Taubinsky. 2008. "Individual Laboratory-Measured Discount Rates Predict Field Behavior." Journal of Risk and Uncertainty, 37: 237-269.

Chan, Tak Wing, and Anita Koo. 2010. "Parenting Style and Youth Outcomes in the UK." European Sociological Review, 27(3): 385-399.

Chetty, Raj, Nathaniel Hendren, Patrick Kline, and Emmanuel Saez. 2014. "Where is the Land of Opportunity? The Geography of Intergenerational Mobility in the United States." Quarterly Journal of Economics, 129(4): 1553-1623.

Chowdhury, Shyamal, Matthias Sutter, and Klaus F. Zimmermann. 2018. "Evaluating Intergenerational Persistence of Economic Preferences: A Large Scale Experiment with Families in Bangladesh." IZA Discussion Paper, 11337.

Cobb-Clark, Deborah A., Nicolas Salamanca, and Anna Zhu. 2016. "Parenting Style as an Investment in Human Development." Journal of Population Economics, 1-38.

Cohen, Jonathan, Keith Marzilli Ericson, David Laibson, and John Myles White. forthcoming. "Measuring Time Preferences." Journal of Economic Literature.

Corak, Miles. 2013. "Income Inequality, Equality of Opportunity, and Intergenerational Mobility." Journal of Economic Perspectives, 27(3): 79-102.

Dittrich, Marcus, and Kristina Leipold. 2014. "Gender Differences in Time Preferences." Economics Letters, 122: 413-415.

Doepke, Matthias, and Fabrizio Zilibotti. 2017. "Parenting With Style: Altruism and Paternalism in Intergenerational Preference Transmission." Econometrica, 85(5): 1331-1371.

Doepke, Matthias, and Fabrizio Zilibotti. 2019. Love, Money, and Parenting: How Economics Explains the Way We Raise Our Kids. Princeton University Press.

Doepke, Matthias, Giuseppe Sorrenti, and Fabrizio Zilibotti. 2019. "The Economics of Parenting." Annual Review of Economics, 11. 
Dohmen, Thomas, Armin Falk, David Huffman, and Uwe Sunde. 2012. "The Intergenerational Transmission of Risk and Trust Attitudes." Review of Economic Studies, 79(2): 645-677.

Doyle, Orla. 2019. "The First 2,ooo Days and Child Skills." Journal of Political Economy, forthcoming.

Epper, Thomas, Ernst Fehr, Helga Fehr-Duda, Claus Thustrup Kreiner, David Dreyer Lassen, Søren Leth-Petersen, and Gregers Nytoft Rasmussen. 2019a. "Experimental Validation of Patience Survey Measures: Technical Report." Center for Economic Behavior and Inequality (CEBI), University of Copenhagen, Denmark.

Epper, Thomas, Ernst Fehr, Helga Fehr-Duda, Claus Thustrup Kreiner, David Dreyer Lassen, Søren Leth-Petersen, and Gregers Nytoft Rasmussen. 2019b. "Time Discounting and Wealth Inequality." Working Paper.

Epper, Thomas, Helga Fehr-Duda, and Adrian Bruhin. 2011. "Viewing the Future Through a Warped Lens: Why Uncertainty Generates Hyperbolic Discounting." Journal of Risk and Uncertainty, 43(3): 169-203.

Falk, Armin, Anke Becker, Benjamin Enke, David Huffman, Uwe Sunde, and Thomas Dohmen. 2018. "Global Evidence on Economic Preferences." Quarterly Journal of Economics, 133(4): 1645-1692.

Frederick, Shane, George Loewenstein, and Ted O'Donoghue. 2002. "Time Discounting and Time Preference: A Critical Review." Journal of Economic Literature, $40(2): 351-401$.

Gauly, Britta. 2016. “The Intergenerational Transmission of Attitudes: Analysing Time Preferences and Reciprocity." Journal of Family and Economic Issues, 38(2): 293312.

Giulietti, Corrado, Enrico Rettore, and Sara Tonini. 2016. "The Chips are Down: The Influence of Family on Children's Trust Formation." IZA Discussion Paper.

Golsteyn, Bart H. H., Hans Grönqvist, and Lena Lindahl. 2014. "Adolescent Time Preferences Predict Lifetime Outcomes." Economic Journal, 124(580): F739-F761.

Jones, Charles I. 2015. "Pareto and Piketty: The Macroeconomics of Top Income and Wealth Inequality." Journal of Economic Perspectives, 29(1): 29-46.

Kosse, Fabian, and Friedhelm Pfeiffer. 2013. "Quasi-Hyperbolic Time Preferences and Their Intergenerational Transmission." IZA Discussion Paper, 7221.

Kosse, Fabian, Thomas Deckers, Pia Pinger, Hannah Schildberg-Hörisch, and Armin Falk. 2019. "The Formation of Prosociality: Causal Evidence on the Role of Social Environment." Journal of Political Economy.

Krusell, Per, and Anthony Jr. Smith. 1998. "Income and Wealth Heterogeneity in the Macroeconomy." Journal of Political Economy, 106(5): 867-896. 
Landersø, Rasmus, and James J Heckman. 2017. "The Scandinavian fantasy: The sources of intergenerational mobility in Denmark and the US." Scandinavian Journal of Economics, 119(1): 178-230.

Linnér, Richard Karlsson, Pietro Biroli, Edward Kong, S. Fleur W. Meddens, Robbee Wedow, Mark Alan Fontana, Maël Lebreton, Stephen P. Tino, Abdel Abdellaoui, Anke R. Hammerschlag, et al. 2019. "Genome-Wide Association Analyses of Risk Tolerance and Risky Behaviors in Over 1 Million Individuals Identify Hundreds of Loci and Shared Genetic Influences." Nature Genetics, 51(2): 245.

Liu, Elaine M., and Sharon Xuejing Zuo. 2019. "Measuring the Impact of Interaction between Children of a Matrilineal and a Patriarchal Culture on Gender Differences in Risk Aversion." Proceedings of the National Academy of Sciences, 116(14): 6713-6719.

Maccoby, Eleanor, and John Martin. 1983. "Socialization in the Context of the Family: Parent-child Interaction." Handbook of Child Psychology: Socialization, Personality and Social Development, 4: 1-101.

Meier, Stephan, and Charles D Sprenger. 2012. "Time Discounting Predicts Creditworthiness." Psychological Science, 23(1): 56-58.

Mischel, Walter, Yuichi Shoda, and Philip K Peake. 1988. "The Nature of Adolescent Competencies Predicted by Preschool Delay of Gratification." Journal of Personality and Social Psychology, 54(4): 687-696.

Robalino, Nikolaus, and Arthur J Robson. 2013. "Genes, Culture, and Preferences." Biological Theory, 8(2): 151-157.

Shoda, Yuichi, Walter Mischel, and Philip K Peake. 1990. "Predicting Adolescent Cognitive and Self-Regulatory Competencies from Preschool Delay of Gratification: Identifying Diagnostic Conditions." Developmental Psychology, 26(6): 978-986.

Solon, Gary. 1992. "Intergenerational Income Mobility in the United States." American Economic Review, 393-408.

Sutter, Matthias, Claudia Zoller, and Daniela Glätzle-Rützler. 2019. "Economic Behavior of Children and Adolescents - A First Survey of Experimental Economics Results." European Economic Review, 111: 98-121.

Sutter, Matthias, Martin G. Kocher, Daniela Glätzle-Rützler, and Stefan T. Trautmann. 2013. "Impatience and Uncertainty: Experimental Decisions Predict Adolescents' Field Behavior." American Economic Review, 103(1): 510-531.

Zumbuehl, Maria, Thomas Dohmen, and Gerard Pfann. 2018. "Parental Involvement and the Intergenerational Transmission of Economic Preferences and Attitudes." University of Zurich, Department of Business Administration. 
Table A1

Attrition in DLSY

\begin{tabular}{|c|c|c|c|c|}
\hline Type of attrition & $T_{p}$ NA & $\begin{array}{c}T_{p} \text { or } T_{c} \\
\text { NA } \\
(2)\end{array}$ & $\begin{array}{l}\text { Values } \\
\text { NA | (2) } \\
\text { not NA } \\
\quad(3)\end{array}$ & $\begin{array}{l}\text { Values or } \\
\text { involvement } \\
\text { NA | (2) not } \\
\text { NA } \\
\quad(4)\end{array}$ \\
\hline Father & & & + & \\
\hline $\mathrm{P}$ birth order $3^{+}$ & & & & + \\
\hline $\mathrm{P}$ inductive reasoning & - & - & & - \\
\hline Grandfather edu NA & & & + & + \\
\hline Grandmother edu NA & & + & & \\
\hline Grandparents NA & + & & & \\
\hline P IQ NA & & & - & \\
\hline Grandparents' income NA & & & & - \\
\hline \multicolumn{5}{|c|}{$\begin{array}{l}\text { Note: All dependent variables are binary and are conditioned on having any children born by } 1996 \text {. The level of } \\
\text { observation is the parent. } T_{p} N A \text { indicates that parental patience is unobserved. } T_{p} \text { or } T_{c} N A \text { indicates that either } \\
\text { parental patience is unobserved or all his/her children have missing information on patience. Values } N A \mid(2) \text { not } \\
N A \text { indicates that parenting values are missing for the sample of parents with patience observed for both the parent } \\
\text { and at least one child. Values or involvement } N A \mid(2) \text { not } N A \text { indicates that parenting values or parental involvement } \\
\text { are missing for the sample of parents with patience observed for both the parent and at least one child. Each } \\
\text { column reports the by-1969-predetermined variables that are statistically significant at the } 5 \text { percent level and their } \\
\text { estimated sign in a Probit model; the model includes } 34 \text { predetermined variables. }\end{array}$} \\
\hline
\end{tabular}

\section{A Data Appendix}

In this data appendix, we provide additional information, not already described in Section 2 , about the two surveys and the administrative data that we use.

\section{A.1 Danish Longitudinal Survey of Youth (DLSY) and DLSY-Children}

The data set is provided by VIVE (The Danish Center for Social Science Research). For the parents who have at least one child who would be eligible to participate in the survey, only a few baseline characteristics predict attrition (Appendix Table AI). We do not observe all the original 3,151 DLSY respondents in the sample of parents for several reasons: 618 individuals did not have any children by 1996; of those with at least one child by 1996, 301 individuals did not have a patience observation; of those with at least one child by 1996 and with a patience observation, 390 individuals did not have a child surveyed in 2010.

\section{A.1.1 Moderators}

Parenting values Parents were asked: Here is a list of qualities which children can be encouraged to learn at home. Which do you consider to be especially important for children to 
acquire at home? They could choose up to three answers from the following eight options: Independence (86\% of parents chose this option), Tolerance (36\%), Imagination $(27 \%)$, Good manners $(30 \%)$, Thrift $(3 \%)$, Sense of responsibility $(72 \%)$, Obedience $(6 \%)$, and Consideration for others $(39 \%)$.

The question is similar, though not identical, to the one asked in the WVS, as the response options differ slightly. In the WVS, respondents are asked to choose up to five values and are given the following eleven options: Good manners; Independence; Hard work; Feeling of responsibility; Imagination; Tolerance and respect for other people; Thrift, saving money and things; Determination, perseverance; Religious faith; Unselfishness; and Obedience. Therefore, we cannot define parenting values exactly as in Doepke and Zilibotti (2017). Note also the different focus of Doepke and Zilibotti (2017) and our study: Doepke and Zilibotti (2017) are interested in studying cross-country differences in parenting, while we are interested in studying within-country differences in parenting. Doepke, Sorrenti and Zilibotti (2019) also use the WVS to define parenting styles and define relaxed (similar to permissive) parenting as parents answering either "independence" or "imagination". In our setting, it would not make sense to consider independence, however, as most parents choose this option. Moreover, independence as a quality might be considered a key characteristic for not only permissive parents but also for authoritative parents, as the goal of the latter group of parents is that their children can make choices on their own that lead to success in life, which naturally requires independence.

More specifically, parents answered this question in 1992 (i.e. at age 38). We acknowledge that parents would ideally have been asked this question before having children. However, given that most parents have more than one child and the question is general (as it does not target a specific child), we do not consider it a major concern that parents would have chosen their parenting values endogenously to their children's (or a specific child's) time preferences. If anything, parents might choose their values as a response to how their first child behaves; yet, we do not find any heterogeneity in the moderation analysis by birth order (not reported).

Parental involvement The survey question was asked in 2001 (i.e. age 47) and answered by parents who, at the time, had at least one child living at home, which was the case for the vast majority of the sample. The exact question is How often does the family-including the children living at home-do the following activities together?: visit the library, go to the swimming pool, go out in nature, go to the cinema, go to the theater, visit friends and family, do housework (cooking, cleaning, shopping), talk about homework and school, eat dinner, and attend sport activities. We scale at least once a 
week/month/year/never to 52/12/1/o times a year. Appendix Table A2 shows the averages by activity.

\section{Table A2}

Parental Involvement by Activity

\begin{tabular}{lcc}
\hline Activities (proxy for times a year) & Average & Std. Errors \\
\hline Library & 4.8 & 0.3 \\
Swimming & 4.7 & 0.3 \\
Nature & 16.8 & 0.5 \\
Cinema & 2.4 & 0.1 \\
Theater & 0.7 & 0.1 \\
Visit friends and family & 19.4 & 0.5 \\
Do housework (cooking, cleaning, shopping) & 38.3 & 0.6 \\
Talk about homework and school & 47.4 & 0.4 \\
Eat dinner & 51.2 & 0.2 \\
Attend sport activities & 17.4 & 0.6 \\
\hline
\end{tabular}

Note: Average indicates the mean of the rescaled variables. The sample has 1,250 observations per activity; each parent is only included once in these statistics.

SES index Based on the rich measures of parental socioeconomic status in the administrative data, we construct an SES index (standardized with a mean of zero and a standard deviation of one), using the first principal component from a principal component analysis (Appendix Table $\mathrm{A}_{3}$ ). In the SES index, we include the mother's and father's length of education, cumulative work experience through 2004, cumulative length of unemployment through 2004, and the natural logarithm of average annual labor earnings 1980-2004; the DLSY-parent's number of children; indicators for the child living with both parents at age 16, the mother/father has children with another person than the parent, and the mother/father has missing educational information. For labor market outcomes, we restrict the focus to 1980-2004 (i.e. through age 50 of the parents) to proxy for children's childhood family environment (the average child turned 21 years in 2004).

\section{A.1.2 Vectors of Controls}

Child demographics includes indicators for being female, five-year age intervals, birth order, and being a twin.

Parent demographics includes indicators for being born before 1954, born after 1954, gender, child-parent gender combination, and birth order. 
Table A3

Principal Component Analysis: SES Index

\begin{tabular}{lcc}
\hline & $\begin{array}{c}\text { First } \\
\text { Compo- } \\
\text { nent }\end{array}$ & Average \\
\cline { 2 - 3 } Mother's Education (years) & 0.27 & 12.63 \\
Father's Education (years) & 0.32 & 12.97 \\
Mother's Education missing & -0.21 & 0.0017 \\
Father's Education missing & -0.26 & 0.0045 \\
Parent's \# of Children & -0.12 & 2.47 \\
Mother has children with other than Father & -0.21 & 0.14 \\
Father has children with other than Mother & -0.14 & 0.17 \\
Mother's years of unemployment 1980-2004 & -0.30 & 2.01 \\
Mother's years of work experience 1964-2004 & 0.37 & 20.58 \\
Father's years of unemployment 1980-2004 & -0.22 & 1.17 \\
Father's years of work experience 1964-2004 & 0.25 & 23.36 \\
Log(Mother's mean labor earnings 1980-2004) & 0.40 & 11.69 \\
Log(Father's mean labor earnings 1980-2004) & 0.38 & 12.18 \\
\hline & Eigen- & Propor- \\
& value & tion \\
\cline { 2 - 3 } Component 1 & 2.87 & 0.22 \\
Component 2 & 1.59 & 0.12 \\
Component 3 & 1.41 & 0.11 \\
Component 4 & 1.25 & 0.10 \\
Component 5 & 1.05 & 0.08 \\
Component 6 & 0.92 & 0.07 \\
Observations & \multicolumn{2}{c}{3.518} \\
\hline
\end{tabular}

Note: Principal component analysis (PCA) of the socioeconomic status experienced during children's childhood. The sample includes all children born by 1996 (including those who did not answer the survey in 2010). We use the first component to construct the SES index. 
Grandparent SES includes grandparental attitudes towards child education and work; an index for the grandparents' educational investment in the parent; quadratic taxable income in 1967 reported by the tax authorities; quadratic number of grandparents' children; indicators for the grandmaternal/paternal level of education, vocational training/education, grandmother/grandfather has work subordinates, grandmother is housewife, gender of the surveyed grandparent, the parent living with both parents at age 14, and missing observations for the different control variables.

Parent SES includes the surveyed parent's spatial, verbal, and inductive abilities measured at age 14; the mother's and father's length of education, cumulative work experience through 2004, cumulative length of unemployment through 2004, the natural logarithm of average annual labor earnings 1980-2004; quadratic number of children; indicators for the child living with both parents at age 16, the mother/father has children with another person other than the parent, and missing observations for the different control variables.

Child endowments includes squared birth weight, child IQ, standardized length of the highest completed education by 2016 by cohort and indicators for being born preterm and missing observations for the different control variables.

Child risk preferences The children are asked three questions capturing risk preferences: 1) You have the opportunity to buy a lottery ticket. There are 1o people in the lottery. The prize is 20,00o DKK. The winner of the lottery is found by lottery, i.e. everyone has the same chance of winning. What price do you want to pay for a lottery ticket for this lottery?, 2) You have won 500,000 DKK in the lottery! You are contacted by a reputable bank that offers you an investment opportunity. The terms are as follow: You have a 50 percent probability of doubling your investment within two years. However, there is also a 50 percent probability of losing your investment. How much of the 500,000 DKK will you invest?, and 3) Do you perceive yourself as a person willing to take risks to achieve something in life, or avoid any risks? Answer on a scale from 1-10, where " 1 " means avoiding risks and "10" means you do not mind taking risks. We group answers into four categories for the two first questions and three categories for the third question and control for the categories in the regression. We do not observe parents' risk preferences.

\section{A.2 Danish Longitudinal Survey of Children (DALSC)}

This data set is also provided by VIVE (The Danish Center for Social Science Research). 
Physical and verbal punishment The survey question is: It's different what parents do when they want to teach children what's right and wrong. I now mention different ways to do it and would like to hear how often you react in these ways (weekly/rarely/never). Physical Punishment is the mean of the first component from a principal component analysis at each child age by parent gender and includes answers to: I emphasize that something is wrong by grabbing the child firmly, I mark something is wrong by giving a slap over the fingers, I spank the child, and I slap the child. Similarly, Verbal Punishment is the mean of the first component from a principal component analysis at each child age by parent gender and includes I scold the child, I tell the child that it has done something wrong, I send him/her into their room, and I say he/she cannot do something that he/she would like to. Fathers answer only these questions when their child is age 7 and 11 .

Quality talking The exact topics of discussion are (with the age at observation in parenthesis): the child's own activities at kindergarten/day-care (4); the child's planned activities at kindergarten/day-care (4); activities at school and after-school care, out-of-school activities (7/11); relationship to other children (4/7/11); relationship to teachers and after-school care staff (4/7/11); physical well-being (4/7/11); and mental wellbeing (4/7/11). Fathers only answer these questions at child age 7 and 11 years.

Impulsivity The impulsivity measure is based on eight questions asked to elicit hedonic behavior; respondents answered each question on a five-point Likert scale (ranging from "Fits very well" (1) to "Does not fit at all" (5)). We construct the index by adding the points from each question, reversing the values for some of the questions, such that a higher value always represents more-impulsive behavior. We standardize the index for children and mothers separately, with a mean of zero and a standard deviation of one. The question is "How well does it describe you?" and the eight statements are: 1) You may run a risk, otherwise it will be too boring (-), 2); It annoys you to be late for appointments $(+), 3)$; When listening to your favorite music, you often lose any sense of time and place $(-), 4)$; You can say no to temptations when you know there is work to be done $(+), 5)$; You take every day as it comes, rather than planning (-), 6); You often act impulsively (i.e. without making plans) (-), 7); You often follow your heart rather than your head (-), and 8); You finish your things on time by making progress at all times $(+)$. Note that our measure of impulsivity is considerably richer than the one-question impulsivity measure widely used in surveys (see e.g. Epper et al. (2019a)). 
B Appendix Tables and Figures 


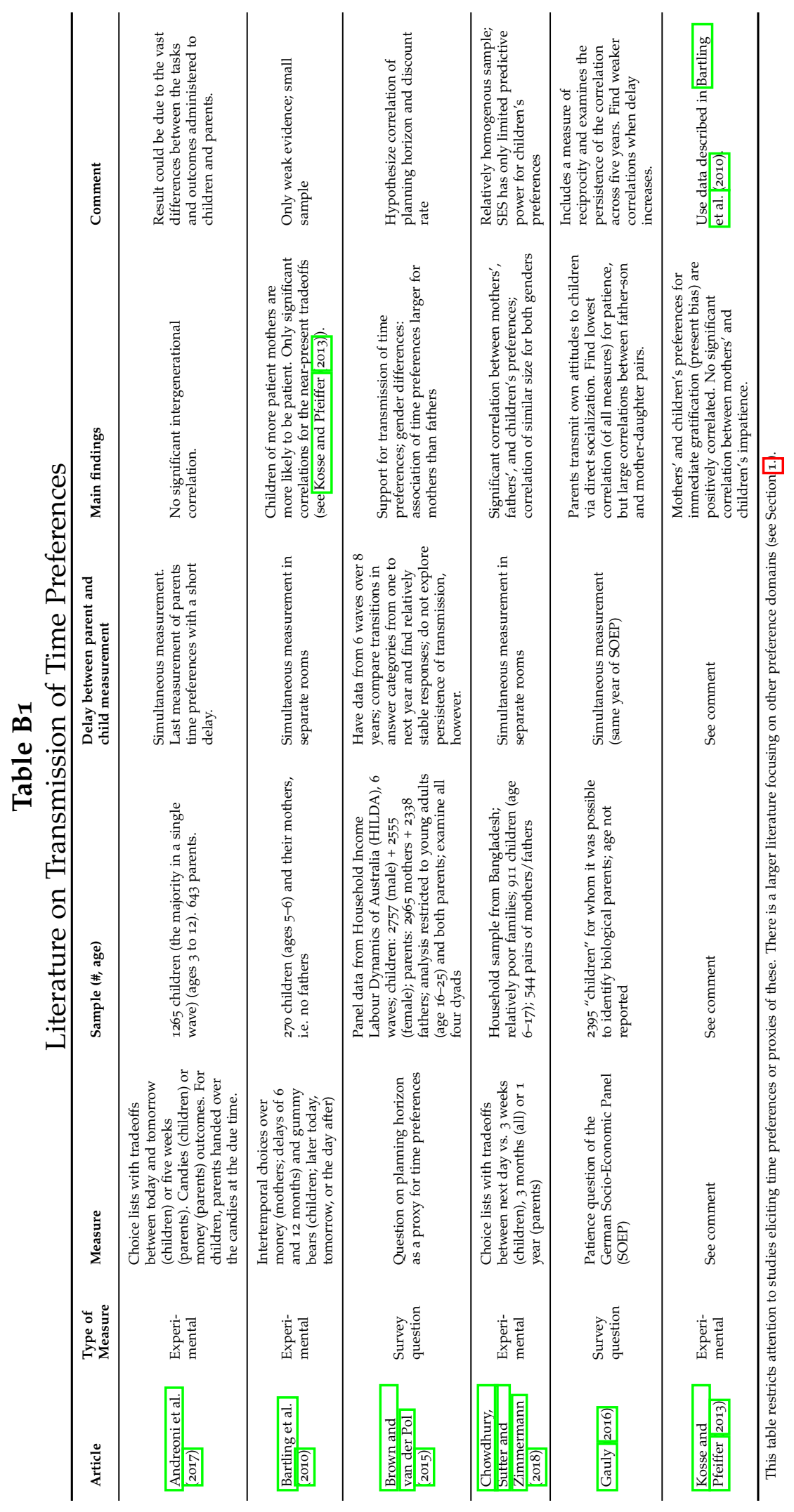


Table B2

Patience by cohort

\begin{tabular}{l|ccccc}
\hline \multirow{2}{*}{ Age } & \multicolumn{2}{|c}{ Children } & & \multicolumn{2}{c}{ Parents } \\
\cline { 2 - 3 } \cline { 5 - 6 } & Percent & Observations & & Percent & Observations \\
\hline 18 & 0.682 & 107 & & 0.778 & 126 \\
19 & 0.776 & 98 & & 0.742 & 2,285 \\
20 & 0.730 & 122 & & 0.692 & 312 \\
\hline Average & 0.728 & 327 & 0.738 & 2,723 \\
\hline
\end{tabular}

Note: This table presents the share of patient children and parents by age at preference elicitation. The sample of parents consists of all original respondents who were 18-20 years old when they were interviewed, including individuals who did not end up having children at all or having children observed in the sample.

Table B3

Ordered Probit Models: Intergenerational Transmission of Patience

Dependent Variable: Child Time Preferences

(1)

(2)

\begin{tabular}{lcc}
\hline Parent is very patient & $\begin{array}{c}0.178^{* * *} \\
(0.063) \\
0.140^{* *} \\
(0.055)\end{array}$ & \\
Parent is medium patient & & $0.154^{* * *}$ \\
& & $(0.052)$ \\
Parent is patient & 3,101 & 3,101 \\
Observations & -0.401 & -0.411 \\
Intercept Cut 1 & $(0.347)$ & $(0.348)$ \\
& 1.037 & $(0.034$ \\
Intercept Cut 2 & $(0.348)$ & $(0.349)$ \\
&
\end{tabular}

Note: Standard errors in parentheses, clustered at the parent level. ${ }^{*} p<0.1{ }^{* *}$ $p<0.05,{ }^{* * *} p<0.01$. The outcome variable indicates whether the child is impatient (1), medium patient (2), or very patient (3). Each column presents the results from separate ordered Probit regressions. Both models control for Child demographics, Parent demographics, Parent School FE, and Grandparent SES. 
Table B4

Associations Between Patience and Fertility Preferences
(1)
(2)
(3)
(4)
(5)
(6)

Panel A: Fertility Preferences at Age 22 and Early Fertility

\begin{tabular}{|c|c|c|c|c|c|c|}
\hline & \multicolumn{3}{|c|}{ Desired \# of Children } & \multicolumn{3}{|c|}{ Has Any Children by } \\
\hline & $\mathrm{O}$ & 1 & 2 & 1973 & 1976 & 1979 \\
\hline \multicolumn{7}{|l|}{ Women } \\
\hline Patient & $\begin{array}{c}0.01 \\
(0.02)\end{array}$ & $\begin{array}{l}-0.02 \\
(0.02)\end{array}$ & $\begin{array}{c}0.00 \\
(0.03)\end{array}$ & $\begin{array}{c}-0.05^{* * *} \\
(0.02)\end{array}$ & $\begin{array}{c}-0.14^{* * *} \\
(0.03)\end{array}$ & $\begin{array}{c}-0.10^{* * *} \\
(0.03)\end{array}$ \\
\hline Observation & 1267 & 1267 & 1267 & 1369 & 1369 & 1369 \\
\hline Average & 0.093 & 0.066 & 0.539 & 0.071 & 0.264 & 0.496 \\
\hline \multicolumn{7}{|l|}{ Men } \\
\hline Patient & $\begin{array}{c}-0.07^{* * *} \\
(0.02)\end{array}$ & $\begin{array}{c}0.01 \\
(0.02)\end{array}$ & $\begin{array}{l}0.07^{* *} \\
(0.03)\end{array}$ & $\begin{array}{l}-0.00 \\
(0.01)\end{array}$ & $\begin{array}{l}-0.02 \\
(0.02)\end{array}$ & $\begin{array}{l}-0.04 \\
(0.03)\end{array}$ \\
\hline Observation & 1211 & 1211 & 1211 & 1370 & 1370 & 1370 \\
\hline Average & 0.116 & 0.043 & 0.597 & 0.012 & 0.087 & 0.231 \\
\hline
\end{tabular}

Panel B: Complete Fertility by 2016 (Age 62)

\begin{tabular}{|c|c|c|c|c|c|c|}
\hline & $\begin{array}{l}\text { Has Any } \\
\text { Child }\end{array}$ & $\begin{array}{c}\text { \# of } \\
\text { Children }\end{array}$ & $\begin{array}{l}\text { Age at } \\
\text { First } \\
\text { Birth }\end{array}$ & $\begin{array}{c}\text { Age at } \\
\text { Last } \\
\text { Birth }\end{array}$ & $\begin{array}{c}\text { \# of } T_{c} \\
\text { Obs }\end{array}$ & $\begin{array}{l}\text { Daughter } \\
\text { w } T_{c} \text { Obs }\end{array}$ \\
\hline \multicolumn{7}{|l|}{ Women } \\
\hline Patient & $\begin{array}{c}0.01 \\
(0.02)\end{array}$ & $\begin{array}{l}-0.04 \\
(0.06)\end{array}$ & $\begin{array}{c}1.49^{* * *} \\
(0.32)\end{array}$ & $\begin{array}{l}0.93^{* *} \\
(0.41)\end{array}$ & $\begin{array}{l}-0.10 \\
(0.07)\end{array}$ & $\begin{array}{l}-0.03 \\
(0.04)\end{array}$ \\
\hline Observation & 1369 & 1369 & 1191 & 1191 & 1191 & 964 \\
\hline Average & 0.870 & 1.836 & 25.653 & 28.919 & 1.376 & 0.669 \\
\hline \multicolumn{7}{|l|}{ Men } \\
\hline Patient & $\begin{array}{c}0.09^{* * *} \\
(0.03)\end{array}$ & $\begin{array}{c}0.21^{* * *} \\
(0.08)\end{array}$ & $\begin{array}{c}0.75 \\
(0.45)\end{array}$ & $\begin{array}{c}0.44 \\
(0.46)\end{array}$ & $\begin{array}{c}0.00 \\
(0.07)\end{array}$ & $\begin{array}{c}0.01 \\
(0.05)\end{array}$ \\
\hline Observation & 1370 & 1370 & 1061 & 1061 & 1061 & 871 \\
\hline Average & 0.778 & 1.680 & 28.900 & 31.884 & 1.413 & 0.659 \\
\hline
\end{tabular}

Note: Standard errors in parentheses, clustered at the parent school level. ${ }^{*} p<0.1,{ }^{* *} p<0.05,{ }^{* * *} p<0.01$. Each panelcolumn-gender presents the results from separate regressions. All models are estimated by OLS. The sample includes all original DLSY respondents. All models include Parent demographics, Parent School FE, and Grandparent SES (see the table note in Table 4 for details). Desired \# of Children indicates whether the respondent in 1976 reported that their desired number of children was respectively, o, 1 , or 2 , leaving 3 or more children the omitted category (due to the survey question, those who already had children and did not want more have a coded desired number of children equivalent to the number of children they had by 1976; the correlations between patience and desired fertility is similar when excluding those who already had children in 1976). Has Any Children by indicates whether the respondent had at least one child by 1973, 1976, and 1979, respectively. Has Any Child indicates whether the person has any children by 2016. \# of Child w T Obs measures the parent's number of children with an observation on patience, conditional on having at least one child by 1996. Daughter w T Obs indicates whether the parent has at least one daughter with an observation on patience, conditional on having at least one child in the survey. 
Table B5

Parenting Values by Parenting Styles

\begin{tabular}{|c|c|c|c|}
\hline & Authoritarian & Permissive & Authoritative \\
\hline Independence & 0.75 & 0.84 & 0.94 \\
\hline Tolerance & 0.12 & 0.31 & 0.56 \\
\hline Imagination & 0.08 & 1.00 & 0.00 \\
\hline Good manners & 0.90 & 0.08 & 0.00 \\
\hline Thrift & 0.04 & 0.01 & 0.04 \\
\hline Sense of responsibility & 0.60 & 0.51 & 0.91 \\
\hline Obedience & 0.17 & 0.02 & 0.00 \\
\hline Consideration for others & 0.32 & 0.23 & 0.53 \\
\hline Observations & 539 & 452 & 709 \\
\hline
\end{tabular}


Table B6

Correlations between Parental Patience, Values, Involvement, and SES

\begin{tabular}{|c|c|c|c|c|}
\hline & $\begin{array}{l}\text { Patient } \\
\text { (1) }\end{array}$ & $\begin{array}{c}\text { Authoritarian } \\
\text { (2) }\end{array}$ & $\begin{array}{c}\text { Permissive } \\
\text { (3) }\end{array}$ & $\begin{array}{c}\text { Involvement } \\
\text { (4) }\end{array}$ \\
\hline \multicolumn{5}{|c|}{ Panel A: Raw correlations } \\
\hline Authoritarian & $\begin{array}{c}-0.059^{* * *} \\
(0.021)\end{array}$ & & & \\
\hline Permissive & $\begin{array}{c}0.007 \\
(0.024)\end{array}$ & $\begin{array}{c}-0.314^{* * *} \\
(0.021)\end{array}$ & & \\
\hline Involvement & $\begin{array}{c}0.004 \\
(0.012)\end{array}$ & $\begin{array}{c}-0.045^{* * *} \\
(0.015)\end{array}$ & $\begin{array}{l}0.026^{*} \\
(0.014)\end{array}$ & \\
\hline SES & $\begin{array}{c}0.056^{* * *} \\
(0.013)\end{array}$ & $\begin{array}{l}-0.057^{* * *} \\
(0.014)\end{array}$ & $\begin{array}{l}0.035^{* * *} \\
(0.013)\end{array}$ & $\begin{array}{l}-0.027 \\
(0.037)\end{array}$ \\
\hline
\end{tabular}

Panel B: Conditional correlations

$\begin{array}{lcccc}\text { Authoritarian } & \begin{array}{c}-0.05 \mathrm{O}^{* *} \\ (0.023)\end{array} & & & \\ \text { Permissive } & -0.012 & -0.283^{* * *} & & \\ & (0.027) & (0.023) & & \\ \text { Involvement } & -0.003 & -0.046^{* * *} & 0.022 & \\ & (0.013) & (0.016) & (0.015) & -0.030 \\ \text { SES } & 0.048^{* * *} & -0.032^{* *} & 0.007 & (0.042) \\ & (0.013) & (0.014) & (0.015) & \left({ }^{*}\right)\end{array}$

Note: (Clustered) standard errors in parentheses (at the school level) in Panel A (Panel B). ${ }^{*} p<$ $0.1,{ }^{* *} p<0.05,{ }^{* * *} p<0.01$. Each row column presents the results from separate regressions, with the variable in the column being the dependent variable. All models are estimated by OLS. Panel A shows the raw correlations, while the correlations shown in Panel B include Parent demographics, Parent School FE, and Grandparent SES (see the table note in Table 4 for details). The level of observation is the parent. 
Table $\mathrm{B}_{7}$

Validation of Parenting Values and Practice

\begin{tabular}{|c|c|c|c|c|}
\hline & $\begin{array}{l}\text { Mother's } \\
\text { expectation } \\
\text { for child ed }\end{array}$ & $\begin{array}{c}\text { Child edu } \\
\text { performance } \\
\text { very } \\
\text { important }\end{array}$ & $\begin{array}{l}\text { Non-Ed } \\
\text { Quality } \\
\text { Time }\end{array}$ & $\begin{array}{l}\text { Ed Quality } \\
\text { Time }\end{array}$ \\
\hline & (1) & $(2)$ & （3） & (4) \\
\hline \multicolumn{5}{|c|}{ Panel A: Maternal values at child age 4 years } \\
\hline Authoritarian & $\begin{array}{c}-0.40^{* * *} \\
(0.08)\end{array}$ & $\begin{array}{c}0.05^{* * *} \\
(0.02)\end{array}$ & $\begin{array}{l}-0.05 \\
(0.03)\end{array}$ & $\begin{array}{c}-0.09^{* * *} \\
(0.03)\end{array}$ \\
\hline Permissive & $\begin{array}{c}0.01 \\
(0.08)\end{array}$ & $\begin{array}{l}-0.04^{* *} \\
(0.02)\end{array}$ & $\begin{array}{c}0.05 \\
(0.03)\end{array}$ & $\begin{array}{c}0.01 \\
(0.03)\end{array}$ \\
\hline Observations & 3,874 & 4,033 & 5,035 & 5,036 \\
\hline Average & $14 \cdot 37$ & 0.52 & -0.00 & -0.01 \\
\hline \multicolumn{5}{|c|}{ Panel B: Maternal values at child age 4 months } \\
\hline A Firm Hand $(0-1)$ & $\begin{array}{c}-0.10 \\
(0.14)\end{array}$ & $\begin{array}{c}0.05 \\
(0.03)\end{array}$ & $\begin{array}{c}0.03 \\
(0.05)\end{array}$ & $\begin{array}{l}-0.02 \\
(0.05)\end{array}$ \\
\hline Instill Respect (0-1) & $\begin{array}{l}-0.41^{* * *} \\
(0.15)\end{array}$ & $\begin{array}{l}0.11^{* * *} \\
(0.03)\end{array}$ & $\begin{array}{l}-0.04 \\
(0.06)\end{array}$ & $\begin{array}{c}0.04 \\
(0.06)\end{array}$ \\
\hline Empathy with Child (o-1) & $\begin{array}{c}0.37 \\
(0.30)\end{array}$ & $\begin{array}{l}-0.10 \\
(0.06)\end{array}$ & $\begin{array}{l}0.22^{*} \\
(0.12)\end{array}$ & $\begin{array}{l}0.38^{* * *} \\
(0.12)\end{array}$ \\
\hline Observations & 3,773 & 3,938 & 4,860 & 4,861 \\
\hline Average & $14 \cdot 37$ & 0.52 & -0.00 & 0.01 \\
\hline \multicolumn{5}{|c|}{ Panel C: Paternal values at child age 4 months } \\
\hline A Firm Hand $(0-1)$ & & & $\begin{array}{l}-0.10 \\
(0.06)\end{array}$ & $\begin{array}{l}-0.09 \\
(0.06)\end{array}$ \\
\hline Instill Respect (O-1) & & & $\begin{array}{l}-0.12^{*} \\
(0.07)\end{array}$ & $\begin{array}{l}-0.14^{* *} \\
(0.07)\end{array}$ \\
\hline Empathy with Child (o-1) & & & $\begin{array}{l}0.40^{* * *} \\
(0.10)\end{array}$ & $\begin{array}{l}0.39^{* * *} \\
(0.10)\end{array}$ \\
\hline Observations & & & 3,276 & 3,273 \\
\hline Average & & & -0.00 & 0.04 \\
\hline
\end{tabular}

Note: Danish Longitudinal Survey of Children (born in 1995). Standard errors in parentheses. ${ }^{*} p<$ $0.1,{ }^{* *} p<0.05,{ }^{* * *} p<0.01$. Each panel column represents the results from one regression. All models control for mother's and father's length of education and age at childbirth, child gender, birth order, and indicators for size of town of residence at birth, indicators for missing observations on the former controls, and indicators for the number of times the outcome variable was measured. Mother's expectation for child ed represents the mother's expectation at child age 15 years of the child's highest educational attainment measured in years. Child edu performance very important is an indicator for the mother answering at child age 15 years that it is very important for her that the child performs well in school. Non-Ed Quality Time and Ed Quality Time are measured at age 7 and 11 for both parents and is the mean of the first component from a principal component analysis at each child age. 


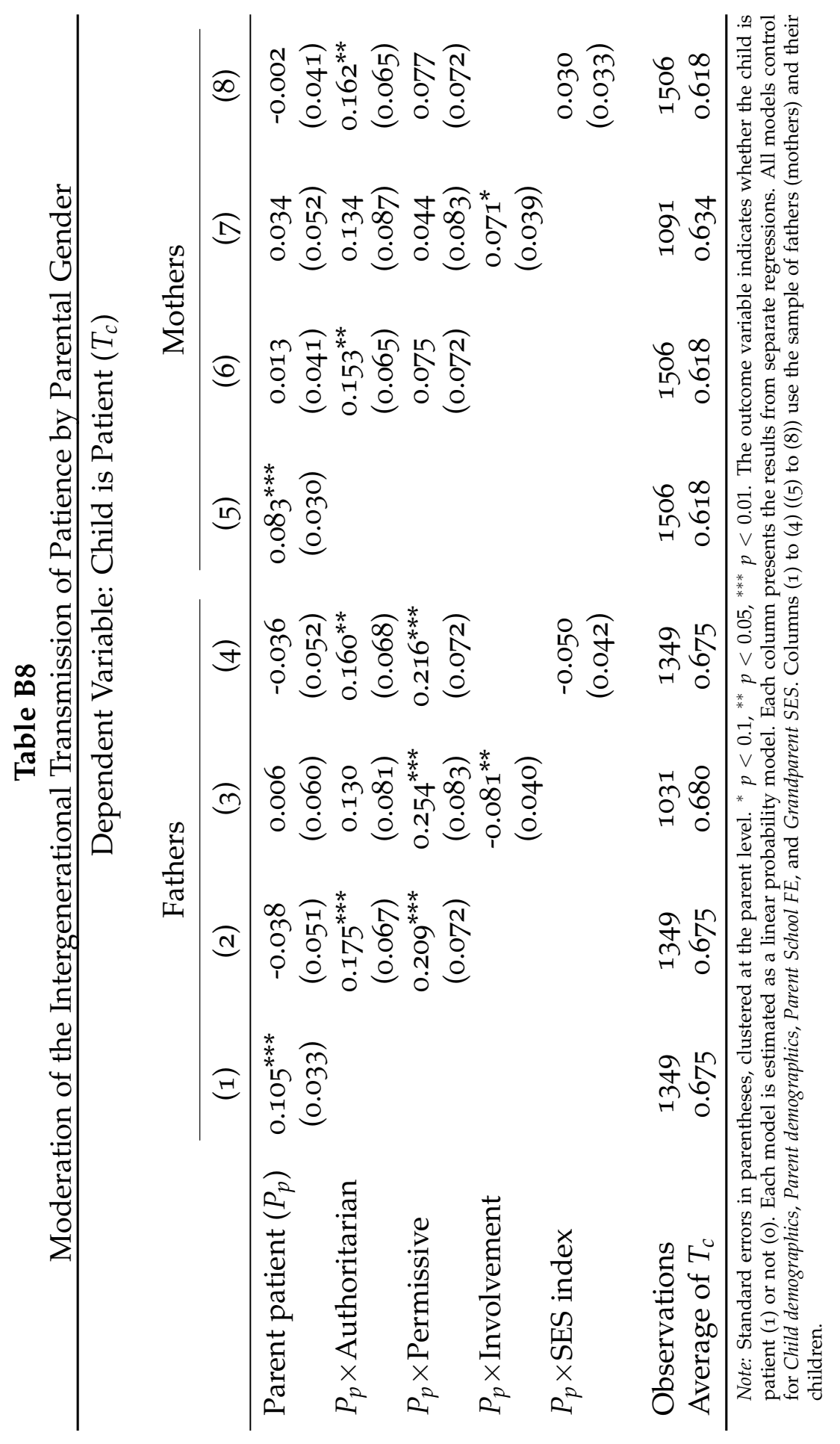


Figure BI

Child Patience by Age and Gender

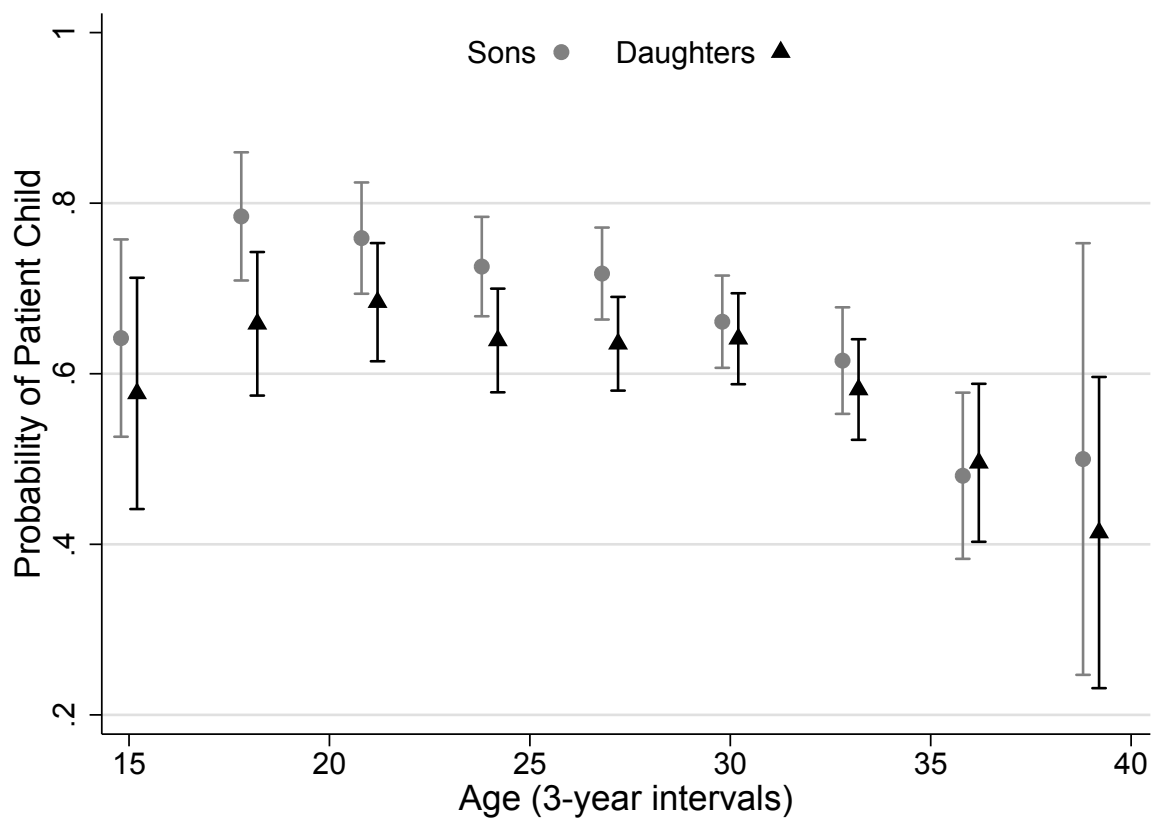

Note: This graph illustrates the share of patient children by age and gender. Age is shown in 3-year intervals. The whiskers represent the 95 percent confidence interval. 
Figure B2

Experimentally Validated Measure

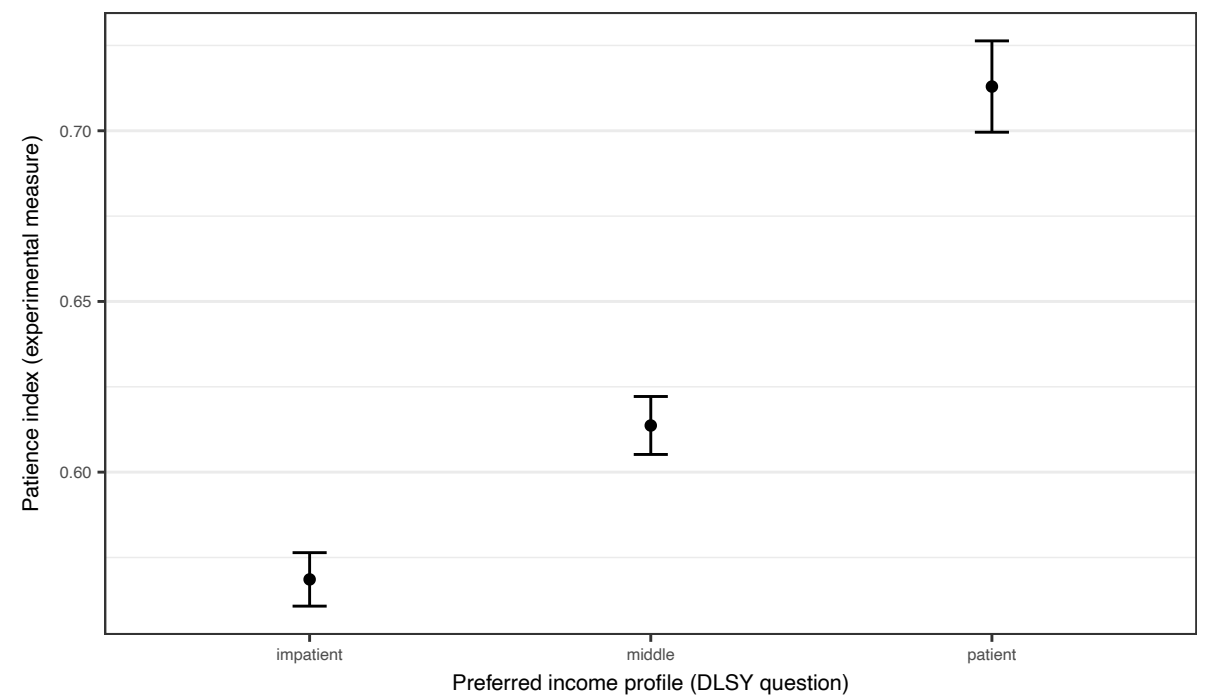

Note: This graph comes from Epper et al. $(2019 b)$. It illustrates the mean of the incentivized experimentally elicited patience index by the three options respondents have when answering our time preference question (for details, see Epper et al., 2019b). 
Figure $\mathbf{B}_{3}$

Time Discounting and Wealth Inequality

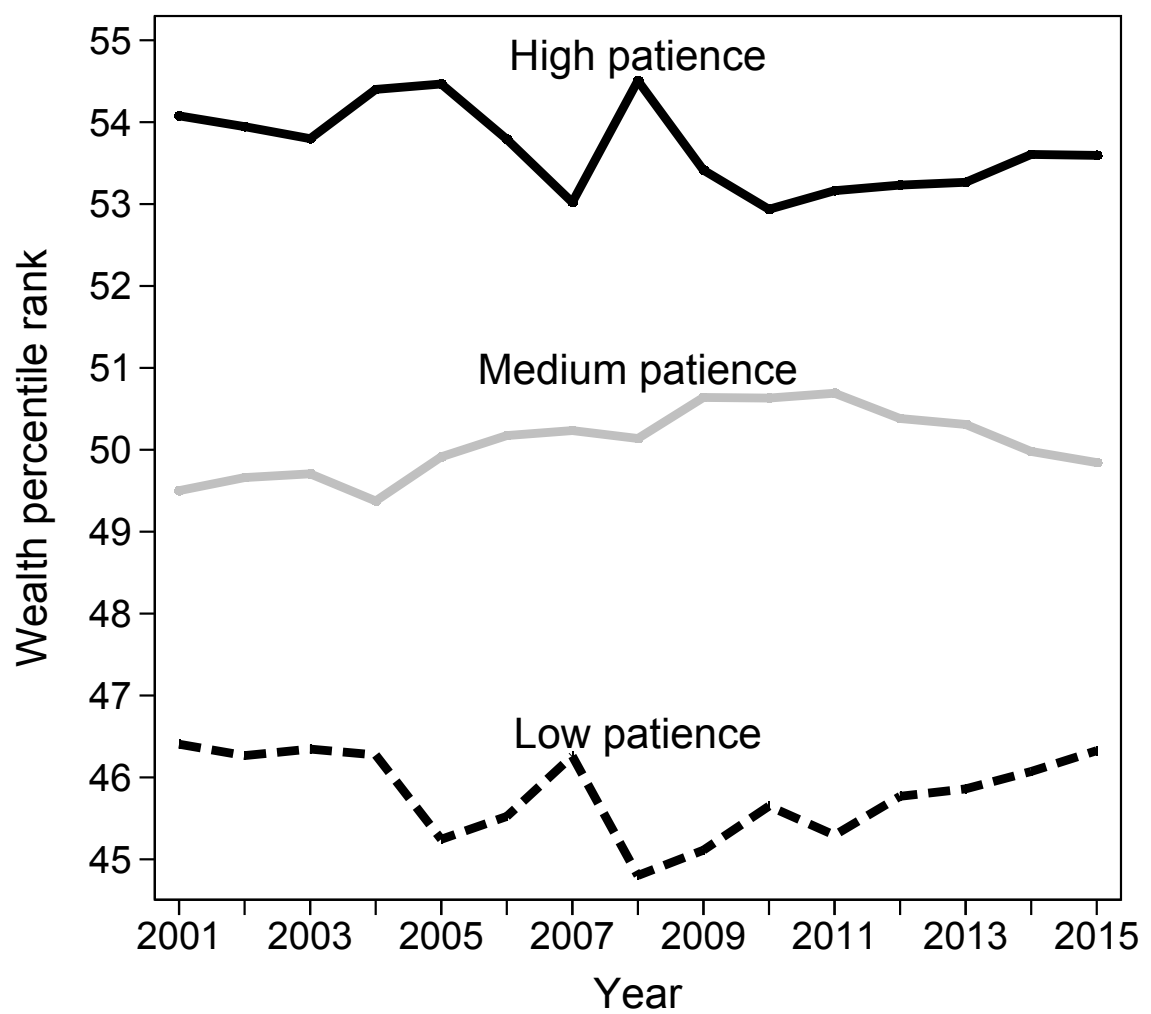

Note: This graph comes from Epper et al. (2019b). It illustrates the mean wealth percentile rank by the three options respondents have when answering our time preference question (for details, see Epper et al., 2019b). 
Figure $\mathrm{B}_{4}$

Intergenerational Transmission of Patience: Marginal Effects of Patient Child Conditional on Patient Parent

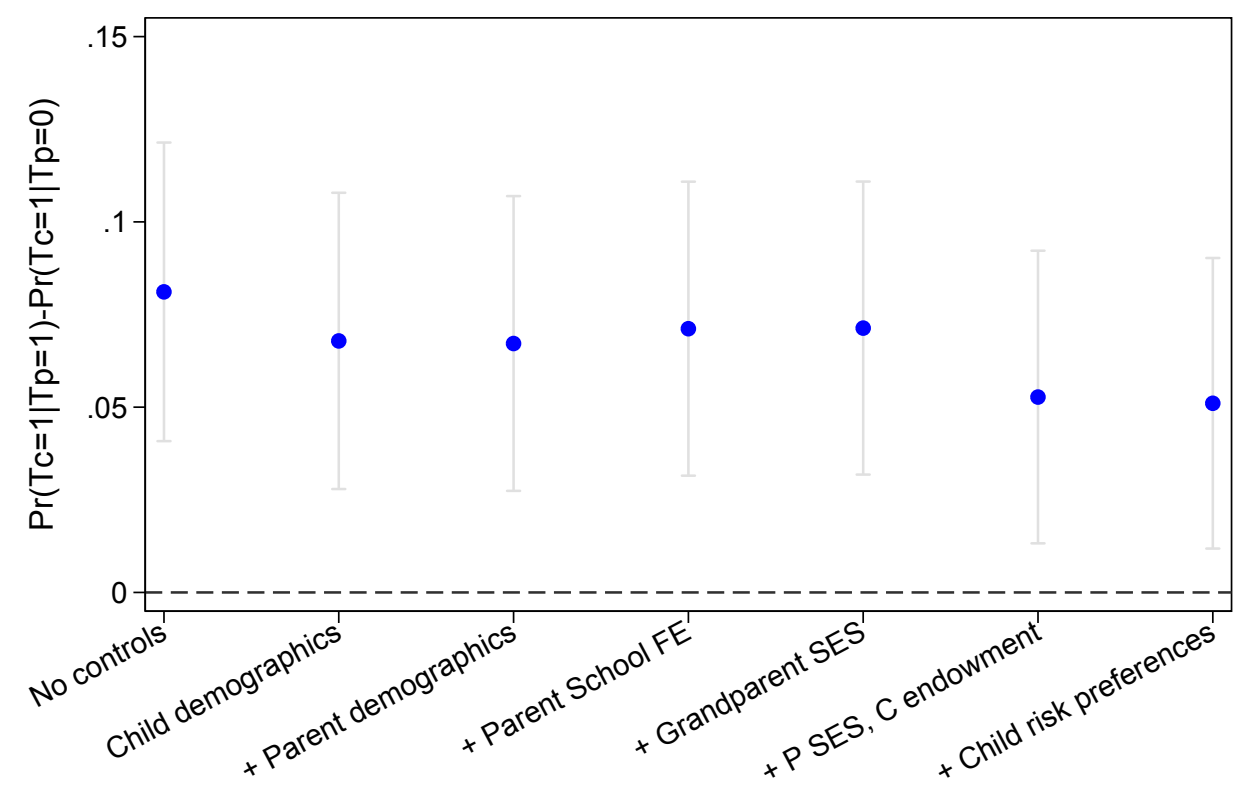

Note: Each blue dot presents the results from separate regressions and illustrates the marginal effect of observing a patient child conditional on having a patient parent, with the gray whiskers representing the 95 percent confidence interval. Observations: 3,101; Average of $\mathrm{T}_{c}: 0.352$. The outcome variable indicates whether the child is patient (1) or not (o). Each model is estimated by probit. The legend explains the controls included in each model; the sets of controls correspond to the ones in Table 4. 